\title{
A TAXIONOMIA DA CULTURA ORGANIZACIONAL EMPREENDEDORA
}

\section{THE TAXIONOMY OF ENTREPRENEURIAL ORGANIZATIONAL CULTURE}

Marcelo Dourado Sales ${ }^{1}$, Manuel Antonio Meireles da Costa², Maria Aparecida Sanches³, Marcio Magera Conceição ${ }^{4}$, Joelma Telesi Pacheco Conceição 5

Submetido em: 16/12/2020

Aprovado em: 14/09/2021

\section{RESUMO}

Este trabalho propõe apresentar a taxionomia das sete tipologias de cultura empreendedora dos estudos de Sales (2010) com base na orientação empreendedora dos líderes propostas por Lumpkin e Dess (1996), Atuahene-Gima e Ko (2001), Sarasvathy e Dew (2005) e Oliveira Junior (2009). Estas tipologias validadas e testadas em uma escala tipo Likert, foram aplicadas em oitenta e duas empresas empreendedoras por meio de um questionário contendo sessenta questões, definindo a taxionomia dominante da cultura empreendedora de diferentes ramos de atuação de micros e pequenas empresas dentro de um raio de $100 \mathrm{~km}$ da cidade de São Paulo. Os resultados obtidos desta taxionomia foram: $1^{\circ}$. Cultura do Tipo 6 Cultura Formação de Parceria [CFP], 45,16\%; $2^{\circ}$. Tipo 7 Cultura Orientada para o Mercado[COM], 25,81\%; $3^{\circ}$. Tipo 1 Cultura Autônoma [CA], 12,90\%; $4^{\circ}$. do Tipo 5 Cultura Competitiva Agressiva [CCA], $6,45 \%$ e em $5^{\circ}$. as Culturas do Tipo 2 Inovação [Cl], 3 Capacidade de Assumir Riscos [CCAR] e 4 Proatividade [CPA] que apresentaram a mesma aderência, $3,23 \%$.

PALAVRAS-CHAVE: Cultura organizacional. Tipos de cultura organizacional. Orientação empreendedora. Empreendedorismo e Micro e pequenas empresas

\section{ABSTRACT}

This research proposes to present the taxonomy of the seven types of entrepreneurial culture based on Sales (2010) studies on entrepreneurial orientation of the leaders proposed by Lumpkin and Dess (1996), Atuahene-Gima and Ko (2001), Sarasvathy and Dew (2005) and Oliveira Junior (2009). such types have been tested and validated on a Likert Scale, then applied in eighty-two small businesses though a questionnaire with sixty-two questions, defining the dominant taxonomy of entrepreneur culture of different types of market operation of small businesses in a length of $100 \mathrm{~km}$ from the city of São Paulo. The results obtained on this classification are: $1^{\circ}$. Type 6 Partnership Estab-

\footnotetext{
${ }^{1}$ Professor e pesquisador com interesse nas áreas de desenvolvimento organizacional, liderança e gestão. Mestre em Administração, profissional de coaching e de gestão da mudança. Atuo como consultor para pequenas e médias empresas. E-mail: madourado2309@hotmail.com 2 Professor, Pesquisador e Coordenador do Programa de Mestrado e Doutorado em Administração de Empresas da UNIFACCAMP

${ }^{3}$ Professora e pesquisadora do Programa de Mestrado e Doutorado em Administração de Empresas da UNIFACCAMP

${ }^{4}$ Pós Doutorado junto a Faculdade Funcional de Ecologia Universidade de Coimbra, Portugal. Pós Doutor junto ao Departamento de Sociologia do Instituto de Filosofia e Ciências Humanas IFCH da Unicamp, SP. Post Doctor in International Relations, do Programa de Estudos de Pósgraduação stricto sensu da Florida Christian University FCU. Memorial de conclusão de curso entregue em novembro de 2013, no Seminário Internacional em Orlando Florida, USA, 2013. Doutor em Ciências Sociais Sociologia Na Pontifícia Universidade Católica de São Paulo-Puc. Doutor em Administração de Negócios na Florida Cristhian Universit FCU USA. Mestre em Ciências Sociais Área de Concentração Sociologia, pela Puc SP. Mestre em Administração de Empresas pela Universidade de Guarulhos -SP. MBA de Gestão de Marketing na ESAMC Sorocaba. Graduado: Bacharel em Ciências Econômicas - Pontifícia Universidade Católica de Campinas SP. Ano 1993. Jornalista MTB 556.03.81V-SP. E-mail: magera1963@gmail.com

${ }^{5}$ Professora mestra na área de Recursos Humanos. E-mail: joelma.telesi@gmail.com
} 
lishment Culture [CFP], 45.16\%; $2^{\circ}$. Type 7 Market-Oriented Culture [COM], 25.81\%; $3^{\circ}$. Type 1 Autonomous Culture [CA], 12.90\%; $4^{\circ}$. Type 5 Competitive Aggressive Culture [CCA], 6.45\%; 5'. Type 2 Innovation Culture [CI]; Type 3 Risk-taking Culture [CCAR] and Type 4 Pro Activity Culture [CPA] showed the same tack, $3.23 \%$.

KEYWORDS: Organizational culture. Types of organizational culture. Entrepreneurial orientation. Entrepreneurship e Micro and small enterprises 


\section{INTRODUÇÃO}

Este trabalho de pesquisa foi elaborado seguindo a tipologia cultural das organizações e para alcançar os resultados projetados, foram aplicadas e validadas as sete tipologias da cultura organizacional e sua taxonomia com base nos trabalhos sobre Tiplogia da Cultura Organizacional de Sales (2010), Orientação Empreendedora de Lumpkin \& Dess (1996), Atuahene-Gima e Ko (2001), Sarasvathy e Dew (2005) e Oliveira Junior (2009), com o objetivo de contribuir com mais informações para planejamento e tomada de decisões para empreendedore e pesquisadores sobre o tema.

Pelo que se vem de expor, esta pesquisa está inserida no campo da Cultura Organizacional. O tema que se desenvolve é Tipologia da Cultura Organizacional Empreendedora; com foco no tópico - Cultura Empreendedora. Mais especificamente se configura o seguinte problema: É possível construir uma taxonomia da tipologia de Cultura Organizacional empreendedora?

Em resumo, pode-se afirmar que estudar o tema 'tipologia da cultura organizacional empreendedora' é de extrema relevância por tanger duas variáveis:

a) a força da representação do empreendedorismo no crescimento econômico que impacta na política e na sociedade global, conforme a pesquisa Global Entrepreneurship Monitor (GEM) aponta o Brasil no topo da lista em relação aos países empreendedores e o líder do BRICS, em um período de 10 anos o Brasil saltou de $23 \%$ para $34,5 \%$, ficando quase 8 pontos percentuais da China - 26,7\%, Índia com uma taxa de empreendedorismo de 10,2\%, África do Sul de $9,6 \%$ e a Rússia de $8,6 \%$. Hoje o Brasil já ultrapassa países como EUA - 20\%; Reino Unido - 15\%; Japão $(10,5 \%)$, Itália $(8,6 \%)$ e França $(8,1 \%)$.

b) a carência de estudos da área, devido ao baixo interesse de se criar um programa de estudos para a base empreendedora e à própria dificuldade de se obter informações a respeito, por existirem organizações não registradas em órgãos formais regulamentadores ou associados.

Assim, quanto maior forem os estudos focados nas MPEs, maior será o interesse em desenvolvê-las em sua estrutura e em suas estratégias para tomadas de decisões frente às necessidades do mercado, assegurando não apenas a sobrevivências, mas também o crescimento econômico local e regional. Segundo Luiz Barreto, presidente do SEBRAE, as últimas pesquisas apontam que além de mais empreendedores permanecem nos negócios, mais pessoas veem uma oportunidade de vida no empreendedorismo e de conquistar o seu próprio negócio.

\section{LIMITAÇÕES DA PESQUISA}

A limitação da presente pesquisa foi buscar líderes que respondessem as questões e que a devolução dos pesquisados em atender a validação desta proposta.

\section{REVISÃO DA LITERATURA: CULTURA ORGANIZACIONAL}

Nesta dissertação, faz-se uma compilação de conceitos desde o início do termo de cultura organizacional e das tipologias culturais mais relevantes que foram estudadas nos últimos anos; além disso, aplicação de um novo modelo específico para o universo empreendedor de Sales (2010) para testar o problema desta pesquisa.

Vejam-se alguns conceitos de cultura por alguns pesquisadores, Tylor apud Horton \& Hunt (1980, p.40) afirma que cultura "é aquele todo complexo que inclui conhecimento, crença, arte, moral, direito, costumes e outras capacidades e hábitos adquiridos pelo homem como membro da sociedade".

Para Schein (1992, p.12), a definição de Cultura é:

Um padrão de premissas básicas compartilhadas que o grupo aprendeu à medida que resolvia seus problemas de adaptação externa e integração interna, que funcionou suficientemente bem para ser considerada válida e, portanto, para ser ensinada aos novos membros como o meio correto de perceber, pensar e sentir 
em relação àqueles problemas.

Schein (1992, p.7) ao definir Cultura, também classifica e explica as principais dez categorias que são associadas a ela, conforme o Quadro 1 abaixo:

Quadro 1- As dez características de Cultura - Schein (1992) - adaptada pelo autor

\begin{tabular}{|c|c|}
\hline $\begin{array}{l}\text { 1. Regularidades Comportamentais } \\
\text { observáveis quando as pessoas } \\
\text { interagem }\end{array}$ & $\begin{array}{l}\text { Linguagem utilizada, tradições e os } \\
\text { costumes que evoluem, os rituais } \\
\text { empregados em uma extensa variedade de } \\
\text { situações. }\end{array}$ \\
\hline 2. Normas do Grupo & $\begin{array}{l}\text { Os padrões implícitos e os valores } \\
\text { que evoluem em grupos de trabalho. }\end{array}$ \\
\hline 3. Valores Expostos & $\begin{array}{l}\text { Os princípios e valores articulados e } \\
\text { publicamente anunciados em estar atingindo, } \\
\text { como qualidade do produto ou liderança em } \\
\text { preço. }\end{array}$ \\
\hline 4. Filosofia Formal & $\begin{array}{l}\text { Princípios ideológicos e as políticas } \\
\text { que guiam as ações do grupo em relação aos } \\
\text { acionistas, clientes e outros stakeholder. }\end{array}$ \\
\hline 5. Regras do Jogo & $\begin{array}{l}\text { As regras implícitas para ser bem } \\
\text { sucedido na organização, os macetes que um } \\
\text { recém-chegado deve aprender para ser } \\
\text { aceito, o jeito em que as coisas são feitas por } \\
\text { aqui. }\end{array}$ \\
\hline 6. Clima & $\begin{array}{l}\text { O layout físico gera um sentimento no } \\
\text { grupo e o modo que os membros da } \\
\text { organização interagem uns com os outros, } \\
\text { com clientes ou estranhos. }\end{array}$ \\
\hline 7. Habilidade Incorporada & $\begin{array}{l}\text { A transmissão das competências } \\
\text { especiais que são passadas de geração para } \\
\text { geração pelos membros do grupo ao realizar } \\
\text { determinadas tarefas e a habilidade de fazer } \\
\text { coisas, sem estarem necessariamente } \\
\text { formalizadas por escrito. }\end{array}$ \\
\hline $\begin{array}{ll}\text { 8. } & \text { Hábitos de Pensamento, Modelos } \\
& \text { Mentais e/ou Paradigmas Linguísticos }\end{array}$ & $\begin{array}{l}\text { São as estruturas cognitivas que são } \\
\text { compartilhadas que guiam as percepções, } \\
\text { pensamentos e linguagem pelos membros de } \\
\text { um grupo, e ela são ensinadas aos novos } \\
\text { membros durante o processo inicial de } \\
\text { socialização. }\end{array}$ \\
\hline 9. Significados Compartilhados & $\begin{array}{l}\text { E o entendimento implícito que se } \\
\text { emerge durante a interação dos membros do } \\
\text { grupo. }\end{array}$ \\
\hline 10. Metáforas ou Símbolos Integrativos & $\begin{array}{l}\text { E a utilização do uso das ideias, } \\
\text { sentimentos e as imagens que os grupos } \\
\text { desenvolvem para sua identificação, podendo } \\
\text { ser ou não apreciado conscientemente, } \\
\text { porém eles já estão incorporados em } \\
\text { edifícios, layout dos escritórios e outros } \\
\text { artefatos materiais do grupo. }\end{array}$ \\
\hline
\end{tabular}


Dentro deste contexto, pode-se entender que essas categorias, ou elementos, da cultura atuam de forma dinâmica e há um equilíbrio natural entre as forças quando estas estão em congruência com os valores, princípios sociais e comportamentais do grupo. Essa congruência gera, assim, uma padronização junto aos ritos e ao clima que levam a cerne da cultura (SCHEIN, 1992). Ao serem analisados, os conceitos acima evidenciam a cultura como um conjunto de vivências experimentadas por um grupo, onde há características psicológicas, cognitivas e emocionais que atuam em um dinamismo dentro dos valores e princípios do grupo estabelecido.

Ao analisarmos todos estes conceitos, podemos dizer que a cultura define e dá forma a uma organização, por ser tratar de um elo social e normativo onde valores e crenças são expressos. Por conseguinte, tal elo reflete diretamente nas ações comportamentais dos atores ali presentes, este conceito é reforçado por Deal e Kennedy (1982), ao sustentarem que cultura é o modo como as coisas são feitas na empresa, além disso, há uma propagação desta manifestação da cultura onde os valores manifestam-se por símbolos como mitos, rituais, histórias, lendas e uma linguagem especializada que reforça a cultura presente naquela organização (REIMANN \& WIENER, 1988).

A Cultura Organizacional é um tema que possui diferentes enfoques, e como consequência, apresenta diferentes construções teóricas. Ao se perpassar com este universo conceitual, tem-se em mente que, segundo Freitas (1991), nenhuma classificação consegue determinar todos os tipos de cultura organizacional e nenhuma tipologia corresponde a uma realidade em todos os seus matizes. Mas, ao identificar o trabalho de diversos pesquisadores e a tipologia descrita por cada um deles, a autora destaca que estas diferentes classificações possibilitam a generalização do objeto estudado e o entendimento de como se estrutura a cultura dentro de um contexto organizacional.

A tipologia de cultura para Handy e Harrison (1976) considera os canais de poder dentro de uma determinada estrutura ou sistema organizacional, são elas, a saber:

1) Cultura do Poder: encontrada em pequenas organizações empresariais, possui a forma de teia e o poder concentrado em um determinado ponto (fundador);

2) Cultura de Papeis: também conhecida como burocracia, trabalha pela lógica e pela racionalidade. Esta cultura é bem sucedida em ambientes estáveis, ou quando a organização pode controlar o ambiente, como nos casos de monopólio ou oligopólio;

3) Cultura da Tarefa: orientada para o trabalho ou projeto, pode ser representada por uma estrutura do tipo em rede, sendo o trabalho em equipe bastante estimulado. Esta cultura é adequada para ambientes que exigem flexibilidade, rápida adaptação/reação e criatividade;

4) Cultura da Pessoa: pouco comum, é centralizada no indivíduo, ou seja, todos os demais aspectos como estrutura, equipamentos e tecnologia são secundários ao interesse da pessoa ou de seu grupo. Alguns exemplos são: Ordens de advogados, comunidades hippies, famílias, entre outros.

Já Deal \& Kennedy (1982) associam o risco da atividade organizacional com a velocidade do feedback emitido pelo ambiente para construir sua tipologia:

1) Cultura Macho: ambiente caracterizado pela individualidade, alta competição, rápidas decisões e personalidade dura. Dentro desta Cultura podem ser destacados os departamentos de polícia, a construção civil, consultoria organizacional e equipes esportivas;

2) Cultura Trabalho Duro Diverte Muito: caracterizada pelo baixo risco e alto feedback, é caracterizada por organizações que atuam em vendas como enciclopédias, automóveis ou imóveis, onde a persistência é determinante do sucesso;

3) Cultura Apostar em sua Companhia: combina alto risco com lento feedback, ou seja, congrega organizações que fazem altos investimentos e têm retorno financeiro lento, como a indústria farmacêutica, os centros de pesquisa e as companhias de petróleo;

4) Cultura de Processo: possui um lento feedback e baixo risco, produz um ambiente centrado no como fazer do que no que fazer. Os bancos, órgãos governamentais e indústrias reguladas por lei são bons exemplos deste tipo de cultura organizacional.

Tendo como foco a área de Recursos Humanos, os autores Sethia e Von Glinow (1985) trabalham o sistema 
de recompensa para definir a relação entre as pessoas e a performance organizacional:

1) Cultura Apática: marcada por um ambiente de indiferença, reflete um estado geral de desmoralização e de cinismo que permeia a organização que possui uma liderança inepta ou alienada. Ocorre em organizações com forte posição no mercado, como em oligopólios, ou com proteção governamental, por exemplo, a concessão pública.

2) Cultura Cuidadosa: preocupada com o bem-estar de seus membros, não impõem altos padrões de desempenho. Empresas do tipo paternalista, onde o fundador ou o líder-chave se destacam são bons exemplos deste tipo de cultura.

3) Cultura Exigente: orientada para o sucesso ou para o desempenho, as organizações deste tipo de cultura possuem sistema de recompensa financeiro acima da média. Empresas do setor de bebidas ou automobilístico são exemplos, pois atuam em mercados onde a competição determina a sobrevivência da organização.

4) Cultura Integrativa: mescla a valorização do pessoal com o incentivo ao desempenho, tendo como filosofia a retenção de talentos. Empresas de alta tecnologia, como a IBM ou 3M, representam este tipo de cultura.

Por sua vez, Donnelly (1984) enfoca a influência do planejamento na criação de valores compartilhados e no grau de estabilidade existente na organização do processo de trabalho:

- Cultura Excelente: é a cultura planejada, ou seja, a organização e as pessoas têm sentido de missão; os planos são comunicados e as pessoas sabem o porquê e para onde estão se dirigindo. Empresas bem estruturadas e que valorizam o planejamento organizacional são exemplos deste tipo de cultura.

- Cultura Fuzzy (vaga/indistinta): é caracterizada pela indefinição de rumo, por constantes mudanças na equipe e pela falta de perspectivas. Organizações que atuam em mercados regulados ou maduros são características desta cultura.

- Cultura Awful (horrível): ocorre em ambientes organizacionais em constantes crises e confusão, sendo caracterizada por atuações emergenciais e clima desagradável e frustrante. Empresas em crise sucessória ou comandadas por dirigentes lunáticos representam este tipo de cultura.

Efetuando-se um contraponto, é relevante apontar a dimensão trazida por Trompenaars (1994), o qual apresenta o seu estudo sobre tipologia com base nas dimensões: igualdade, hierarquia e orientações em relação às pessoas e às tarefas. $O$ autor descreve a tipologia cultural da seguinte forma:

1) A cultura do tipo A família - possui caráter pessoal com relações próximas, mas, é, ao mesmo tempo, hierárquica, tendo como resultado uma cultura voltada ao poder;

2) A cultura do tipo Torre Eiffel - representa a burocracia formal. As relações são mais impessoais e a lógica de subordinação é claramente racional;

3) A cultura do tipo Míssil Guiado - cultura igualitária onde a lealdade à profissão e ao projeto é maior que a lealdade à empresa;

4) A cultura do tipo Incubadora - o objetivo é servir de incubadora para a auto expressão e autossatisfação. É pessoal e igualitária.

Com base nesses tipos, segue o atrelamento desses conceitos com o empreendedorismo empresarial: a tipologia da cultura organizacional proposta neste trabalho toma por base os estudos para orientação empreendedora de Lumpkim; Dess (1996) e Oliveira Junior (2009). O trabalho parte do princípio que há uma relação entre o empreendedorismo e a cultura organizacional que regula o dinamismo do negócio segundo a tipologia do empreendedor.

Ao falar de organizações, trata-se também de pessoas, e - consequentemente - de gestores e líderes. Como se vem de expor neste trabalho, acredita-se que a cultura dentro de uma organização influencia o pensar, sentir e até o agir das pessoas. Esta força que se propaga dentro da organização permite o empreendedor aplicá-la a favor do seu negócio para o cumprimento de seu objetivo. Schein (1992) apud Oliveira (2009) detalham esta força ao afirmar que os líderes influenciam a cultura da organização na medida em que favorecem a existência de um sentimento de sucesso organizacional e se são capazes de reduzir a ansiedade inerente ao processo de mudança. Assim sendo, o líder é o grande responsável pelas mudanças; e o uso da cultura é uma estratégia fundamental para o negócio.

Se a cultura reflete-se no comportamento das pessoas, uma cultura não alinhada com o momento do negócio, 
pode também atuar negativamente. E, por este motivo, assim como modelos de liderança mudaram ao decorrer do tempo - como a Teoria Clássica, a Escola Humana, a Contingencial e entre outras - para preencher uma necessidade; a cultura organizacional também precisa acompanhar as novas tendências que refletem esta demanda.

Dentro desta nova tendência nasce também uma nova cultura, a Cultura Empreendedora que busca lidar com o ser na dinâmica do mundo contemporâneo. Isto envolve lidar com o abstrato, com as percepções, com as sensações, com os desejos, com os sonhos e etc. Tais necessidades pedem novas maneiras de gerenciar e liderar pessoas, demandando do empreendedor uma maior versatilidade e rapidez. Wood Jr., apud Caldas e Motta (1997, p.152) pontuam esta necessidade ao dizer que: "na era pós-moderna a liderança ganha a dimensão do gerenciamento da imagem, dos símbolos e dos sentidos. Com isso, liderar deixa de ser dirigir e comandar para convencer e seduzir."

Dentro desta linha de pensamento, a mudança é inerente dentro de uma organização. Assim como a estrutura organizacional pede a mudança, o líder também necessita de adequação. E cada necessidade deve ser vista como um problema a ser administrado e resolvido, de forma que, o líder se insira neste contexto e se veja como parte deste contexto para que uma sinergia possa emergir. Envolvem-se, então, todas as competências humanas e essenciais a favor de uma necessidade.

Oliveira Junior (2009) conclui que a disposição de se ver como parte de um problema existente é uma das novas qualidades da nova liderança de um sistema que precisa mudar. Tais líderes são aptos a produzirem uma imagem onde existe um discurso e soluções simples para que se resolvam problemas complexos. Todavia, se fazem necessárias algumas características vinculadas à competência técnica, contextual e política. Assim como os processos psicológicos da interação entre eles e seus liderados e as suas concepções sobre a natureza humana; os quais poderão o credenciar à função.

A capacidade de empreender é outra competência que os líderes precisam desenvolver, pois um empreendedor - ao criar um novo negócio - enfrentará riscos e incertezas na identificação de oportunidades de mercado e do agrupamento de recursos necessários para capitalizar sobre estas oportunidades. Oportunidades com o propósito de conseguir lucro e crescimento: financeiro, intelectual; ou ainda, pessoal (OLIVEIRA JR, 2009).

Para organizações, normalmente, mudanças são complexas; portanto elas demandam desafio, dinamismo e estratégia por parte dos líderes e gestores. Por isto, é dentro deste contexto, que a cultura organizacional empreendedora forte irá impulsionar os fatores necessários de forma que atuem a favor desta nova ordem; alinhando as competências existentes e não existentes dentro da organização com a estratégia definida em prol do objetivo ou meta estabelecida.

Mediante a este cenário, esta pesquisa apresenta uma taxionomia da nova tipologia de cultura empreendedora, conforme Figura 2 abaixo, apresentado na Metodologia as suas definições:

Figura 2 - Proposta de Tipologias de Cultura Empreendedora- criada pelo autor

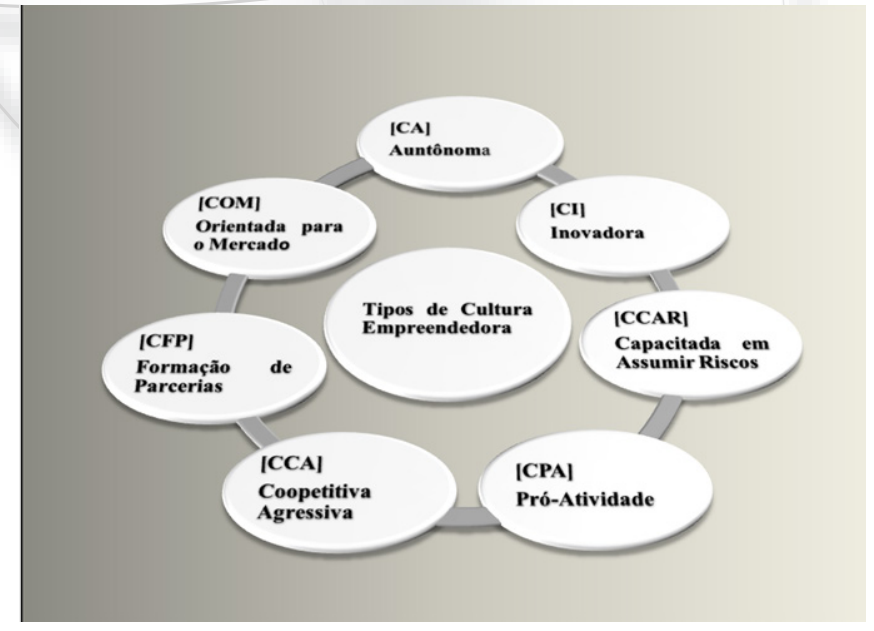


Considerando os princípios acima descritos serão apresentadas as seguintes categorias descritivas destacadas como fundamentais para o pleno entendimento desta pesquisa:

- Cultura organizacional autônoma é o ato de agir e tomar decisões dentro da organização de forma independente e reconhecida, ora por indivíduos ou grupos com o objetivo de trazer uma ideia ou uma visão com o intuito de desenvolvê-la por completo com o intuito de se atingir um objetivo que contribua para o sucesso da organização, sem medo de um possível constrangimento ou punição, caso este objetivo não seja alcançado;

- Cultura organizacional inovadora é utilizar, sobretudo, novas ideias, singularidades, experimentos e apoiar processos criativos que resultem em novos produtos, serviços e ainda processos tecnológicos, envolvendo engenharia, pesquisa, expertise técnica e até mesmo o conhecimento industrial;

- Cultura organizacional não conservadora (propensa a correr riscos) é o ato de tomar decisão, ora para a criação de novos produtos, ora criação de serviços, ora investimento no negócio, ou ainda para criação de novas empresas, inerente ao possível risco de uma grande perda financeiro;

- Cultura organizacional proativa é colocar ação em prática, esta ação vincula-se a antecipação de mudanças, podendo resultar em mudanças de um ambiente com o objetivo de melhoria, seja ela de processos, criação ou venda de novos produtos, ou ainda de uma nova estratégia;

- Cultura organizacional agressiva é um ato de sobrevivência e ou de posicionamento estratégico frente aos seus concorrentes, com o objetivo de intensificar o seu desempenho, distanciando o seu concorrente, garantindo assim a sua liderança;

- Cultura organizacional competitiva (orientada para buscar parcerias) é o ato de buscar uma união ou aliança com o objetivo de estabelecer uma estratégia para o atingimento dos objetivos dos envolvidos;

- Cultura organizacional orientada para o mercado é a busca contínua da fidelização de clientes, assim como atender as suas necessidades e desejos, onde a essência desta estratégia é o próprio mercado de atuação, focando em novos produtos ou até mesmo um novo negócio para atender um nicho desejado;

\section{METODOLOGIA DA PESQUISA JUSTIFICATIVA DO MÉTODO E DAS TÉCNICAS A SEREM UTILIZADAS}

O problema objeto da presente pesquisa está associado à construção de uma escala tipo Likert, para medir a cultura organizacional de uma empresa com base na orientação empreendedora dos líderes. É desta forma uma pesquisa que lida com variáveis qualitativas.

\section{Definições operacionais da pesquisa Obtenção dos Dados}

Selltiz et al. (1974), afirmam que a etapa de coleta e validação dos dados é muito importante, na medida em que dados incorretos comprometem definitivamente a pesquisa. E afirmam:

A fim de obter dados coerentes, livres de erros introduzidos por entrevistadores, observadores e outras pessoas, é necessário supervisionar, estritamente, a equipe dos que trabalham no campo, quando coligem e registram informação. [...] À medida que os dados são coligidos, devem ser examinados para verificar se são completos, compreensíveis, coerentes e precisos. (SELLTIZ et al. 1974, p.86)

Na coleta de dados da presente pesquisa foi apresentado uma proposta de Sales (2010) sob cultura organizacional empreendedora. 


\section{Procedimentos de Analise dos Dados \\ Validade de constructo (Alpha de Cronbach)}

De acordo com Pereira (1999, p.86), para se medir a confiabilidade de uma Escala, isto é a validade de constructo pode-se utilizar o coeficiente $\alpha$ de Cronbach . O valor alfa varia de 0 a 1 . O software SPSS 17.0 tem a função Reliability Analysis que possibilita a análise de confiabilidade de um instrumento de coleta. Observar que o SPSS 17.0 oferece além do coeficiente Alpha de Cronbach outros testes de consistência.

O cálculo do valor de a de Cronbach é feito seguindo as etapas abaixo:

Foi aberto o SPSS e selecionado a planilha Variable View. Na coluna Name foram introduzidos os nomes das proposições válidas (que passaram pelos dois testes anteriores). A seguir ajustou-se o número de casas decimais para o valor zero.

Para cada uma das proposições foram introduzidos os resultados obtidos na pesquisa com os respondentes dos grupos $\mathrm{G} 1$ e G2. Os mesmos dados do quadro 4.2. correspondentes às linhas válidas foram inseridos na planilha do SPSS.

Foi selecionada a função para a análise: Analyse, Scale, Reliability Analysis. Foram marcados os testes Descriptives for Item, Scale e Scale IF item deleted além de Correlations Inter-item. Observar que os estatísticos Descriptives for são os mais importantes. O output do SPSS fornece diversos e importantes resultados.

O quadro Case Processing Summary mostra o número de variáveis válidas e eventuais variáveis excluídas com base no procedimento de análise. No presente caso não ocorreu exclusão de variável alguma, como mostra o quadro 3:

Quadro .3 - Lista de variáveis excluídas pelo procedimento

\begin{tabular}{|l|r|r|}
\hline & & $\%$ \\
\hline Valid & & 10 \\
Case & 0 & 0,0 \\
Excluded $^{\text {s }}$ & &, 0 \\
Total & & 10 \\
& 0 & 0,0 \\
\hline
\end{tabular}

a. Listwise deletion based on all variables in the procedure.

O quadro Reliability Statistics (Quadro 4) é de fundamental importância pois mostra o valor Alpha de Cronbach que é obtido pela fórmula abaixo, onde:

$\mathrm{K}=$ número de variáveis consideradas

cov= média das covariâncias

var= média das variâncias

$$
\alpha=\frac{\frac{K \operatorname{cov}}{\mathrm{var}}}{1+(K-1) \frac{\operatorname{cov}}{\operatorname{var}}}
$$


Quadro 4 - Índice a de Cronbach.

Reliability Statistics

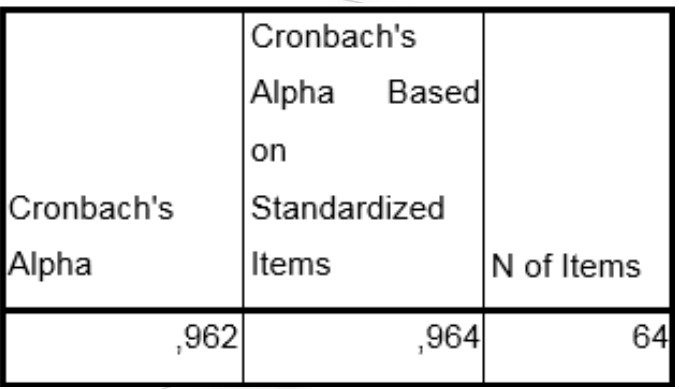

O valor obtido do $\alpha$ de Cronbach, neste caso, foi de 0,962. Este indicador assume valores entre 0 e 1 e trabalha com a premissa que as correlações entre os itens são positivas. De forma geral considera-se que um bom valor do a seria 0,70 ou superior (obtido com uma amostra significativa). Esta regra deve ser aplicada com prudência uma vez que, o grau adequado de fidedignidade depende da utilização do instrumento. Pereira (1999, p.87) afirma que para interpretar o a de Cronbach pode-se entendê-lo como um coeficiente de correlação ao quadrado (R2) com uma suposta medida real do fenômeno.

Quadro 5 - Estatísticas dos itens

Scale Statistics

\begin{tabular}{|r|r|r|r|}
\hline Mean & Variance & Std. Deviation & N of Items \\
\hline 23 & 14 & 38,089 & 64 \\
9,85 & 50,766 & & \\
\hline
\end{tabular}

Mais importante do que analisar o coeficiente é estar atento para as informações sobre o comportamento de cada item compondo o indicador (PEREIRA, 1999):

Scale mean if item deleted (escala media se o item é desprezado): A média da Escala é 239,85 conforme mostra o Quadro 4.5. Quanto mais um item diminui a média mais importante é ele de acordo com Pereira (1999, p.87). Observar no quadro 4.6 que basicamente todos os itens possuem importância semelhante isto é, uma média em torno de 236.

Ver apêndice Quadro 6 - Estatísticas dos itens

Scale variance if item deleted (Variância da Escala, se o item é desprezado): neste caso interessa eliminar os itens que promovem uma redução maior na variância. A variância atual da escala é de 1450,766 como mostra o Quadro 6 (Apêndice). A remoção da proposição P23 reduziria a variância para 1370,345.

Corrected Item-Total correlation (Correlação corrigida entre Item e Total): mostra o coeficiente de correlação de Pearson ( $r$ ) entre o item (proposição) e o indicador total depurado de sua própria contribuição. $O$ primeiro tipo de impacto é o que tem menor correlação com o indicador total. De acordo com McHorney et al. (1994) no desenvolvimento de um instrumento de mensuração a correlação item-total deve ser pelo menos 0,40 . No presente caso algumas proposições foram excluídas na medida em que a correlação item-total observada é menor do que 0.4. Ver quadro 7. Estas proposições foram excluídas 
Quadro 4.7 - Lista das proposições Correlação corrigida entre Item e Total inferior a 0,40.

\begin{tabular}{|r|r|r|r|r|}
\hline & $\begin{array}{c}\text { Scale Mean if } \\
\text { Item Deleted }\end{array}$ & $\begin{array}{r}\text { Scale Variance if } \\
\text { Item Deleted }\end{array}$ & $\begin{array}{r}\text { Corrected } \\
\text { Item-Total } \\
\text { Correlation }\end{array}$ & $\begin{array}{r}\text { Cronbach's } \\
\text { Alpha if Item } \\
\text { Deleted }\end{array}$ \\
\hline p48 & 236,40 & 1436,358 &, 138 &, 963 \\
\hline p49 & 236,15 & 1445,187 &, 062 &, 963 \\
\hline p50 & 236,15 & 1444,871 &, 062 &, 963 \\
\hline p51 & 235,80 & 1440,274 &, 157 &, 962 \\
\hline p52 & 236,25 & 1435,671 &, 187 &, 962 \\
\hline p54 & 235,90 & 1450,200 &,- 007 &, 963 \\
\hline p63 & 235,90 & 1442,411 &, 097 &, 962 \\
\hline p64 & 235,90 & 1430,937 &, 373 &, 962 \\
\hline p69 & 236,10 & 1426,937 &, 267 &, 962 \\
\hline
\end{tabular}

Cronbach's Alpha IF Item Deleted ( $\alpha$ de Cronbach se o item é desprezado): mostra o impacto que teria a retirada do item. O valor do a com os 64 itens é de 0,962 (ver Quadro 6). Não é necessário remover proposições.

O questionário validado tem as proposições conforme Apêndice Quadro 8.

O Questionário, para evitar viés, será apresentado com as questões em ordem alfabética e sem estarem agrupadas por tipo de cultura, como mostra o Quadro 4.9 (Apêndice). A proposição original (PO) não é fornecida ao respondente.

\section{Tabulação dos dados}

Para evitar viés, os questionários apresentados aos respondentes tinham as proposições ordenadas alfabeticamente, como mostra o quadro 10 , ver abaixo. Usando as funções do Excel os dados introduzidos eram ajustados para a ordem correta, como ilustra o quadro 11, ver a próxima página.

Quadro 10 - Tabulação das respostas recebidas (questionário original)

\begin{tabular}{|c|c|c|c|c|c|c|c|}
\hline \multirow{3}{*}{ PF } & \multicolumn{6}{|c|}{$\begin{array}{c}\text { Por favor marque com uma única alternativa que mais identifica com sua percepção alguns aspectos } \\
\text { referentes à cultura.organizacional na sua empresa }\end{array}$} & \multirow[b]{3}{*}{ Tabulação } \\
\hline & \multicolumn{6}{|c|}{$\begin{array}{l}\text { Dê a sua opinião marcando um X na coluna mais adequada à sua avaliação sobre a proposiçãa. Use: } \\
\text { DT - DISCORDO TOTALMENTE, D - DISCORDO, I - INDIFERENTE, C - CONCORDO, CT - CONCORDO TOTALMENTE }\end{array}$} & \\
\hline & Proposições & DT & D & I & C & CT & \\
\hline 1 & A empresa aceita assumir riscos para idéias empreendedoras. & & & & $\mathrm{X}$ & & 4 \\
\hline 2 & $\begin{array}{l}\text { A empresa adota uma postura agressiva em situações de tomada de decisões } \\
\text { envolvendo incertezas. }\end{array}$ & & $\mathrm{x}$ & & & & 2 \\
\hline 3 & A empresa antecipa tendências. & & & & $\mathrm{x}$ & & 4 \\
\hline 4 & A empresa apóia e materializa projetos inovadores. & & & & $\mathrm{X}$ & & 4 \\
\hline 5 & $\begin{array}{l}\text { A empresa apóia o lider ou um membro da organização que tenha falhado em um } \\
\text { novo projeto. }\end{array}$ & & & & $\mathrm{x}$ & & 4 \\
\hline 6 & A empresa apóia tendências para novos projetos & & & & $\mathrm{X}$ & & 4 \\
\hline 7 & $\begin{array}{l}\text { A empresa atua antes que seja forçada a reagir às ameaças e oportunidades do } \\
\text { ambiente. }\end{array}$ & & & & $\mathrm{x}$ & & 4 \\
\hline 8 & $\begin{array}{l}\text { A empresa atua de forma ativa em acompanhar o seu produto ou serviço em seu } \\
\text { mercado de atuação. }\end{array}$ & & & & $\mathrm{X}$ & & 4 \\
\hline 9 & A empresa aventura-se no desconhecido. & & $\mathrm{X}$ & & & & 2 \\
\hline 10 & $\begin{array}{l}\text { A empresa busca a criação de processos resultantes de uma visão diferenciada do } \\
\text { seu meio de atuação. }\end{array}$ & & & & $\mathrm{x}$ & & 4 \\
\hline
\end{tabular}


Quadro 4.11 - Tabulação ajustada para análise

\begin{tabular}{|c|c|c|c|c|c|c|c|}
\hline \multicolumn{7}{|c|}{ Cultura Organizacional } & \\
\hline & \multicolumn{6}{|c|}{$\begin{array}{c}\text { Por favor marque com uma única alternativa que mais identifica com sua percepção alguns aspectos } \\
\text { referentes à cultura.organizacional na sua empresa }\end{array}$} & \\
\hline & \multicolumn{6}{|c|}{$\begin{array}{l}\text { Dê a sua opinião marcando um X na coluna mais adequada à sua avaliação sobre a proposição. Use: } \\
\text { DT - DISCORDO TOTALMENTE, D - DISCORDO, I - INDIFERENTE, C - CONCORDO, CT - CONCORDO TOTALMENTE } \\
\end{array}$} & \multirow{3}{*}{ Tabulação } \\
\hline & & & & & & & \\
\hline & AUTONOMIA $(\mathrm{A})$ & DT & D & I & $\mathrm{C}$ & $\mathrm{CT}$ & \\
\hline 1 & $\begin{array}{l}\text { A empresa estimula empregados que apresentam sugestões inovadoras para a } \\
\text { organização. }\end{array}$ & & & & & & 4 \\
\hline 2 & $\begin{array}{l}\text { A empresa recompensa empregados que apresentam sugestões inovadoras para a } \\
\text { organização. }\end{array}$ & & & & & & 2 \\
\hline 3 & Há uma liberdade de ação empreendedora dentro da organização. & & & & & & 4 \\
\hline 5 & $\begin{array}{l}\text { Há liberdade para buscar novas soluções para a melhoria do produto dentro da } \\
\text { organização. }\end{array}$ & & & & & & 4 \\
\hline 6 & Há liberdade para questionamento dos produtos existentes. & & & & & & 4 \\
\hline 11 & $\begin{array}{l}\text { A empresa proporciona meios para desenvolver e explorar a tecnologia } \\
\text { organizacional por qualquer membro. }\end{array}$ & & & & & & 3 \\
\hline 13 & Há apoio para uma tomada de decisão de uma nova idéia & & & & & & 4 \\
\hline 14 & Há um apoio moral e financeiro ao assumir riscos por um ato empreendedor. & & & & & & 3 \\
\hline
\end{tabular}

\section{Procedimentos de Analise dos Dados}

Os dados coletados foram analisados de forma a testar cada uma das hipóteses. Foram utilizadas estatísticas não paramétricas. Ockert (2005) defende que os dados oriundos das escalas tipo Likert permitem apenas a relação de equivalência $(=)$ e a relação de comparação $(>)$. Esta última é irreflexiva, assimétrica e transitiva. Desta forma os dados coletados com escalas deste tipo aceitam apenas alguns tratamentos matemáticos ou estatísticos (testes não-paramétricos). Portanto a escala de tipo Likert não pretende ser mais que uma escala ordinal; vale dizer, permite a ordenação de indivíduos através da 'favorabilidade' de sua atitude com relação a determinado objeto, mas não apresenta uma base para dizer quanto o indivíduo é mais favorável que outro, nem para medir a quantidade de mudança depois de certa experiência."(SELLTIZ, et al. 1975, p. 415).

\section{RESULTADOS}

Neste capítulo são apresentados os resultados obtidos com a pesquisa. Esta foi feita com a intenção de dar resposta à questão-problema: É possível construir uma escala tipo Likert, para medir a cultura organizacional de uma empresa com base na orientação empreendedora dos líderes?

\section{Estatísticas descritivas}

Inicialmente se apresenta algumas estatísticas descritivas decorrentes da pesquisa feita com os 82 respondentes.

\section{Respostas ao item}

A tabela Resultado - R1, ver Apêndice, apresenta as respostas dadas a cada proposição ou item, considerando o diferencial semântico adotado: DT/D///C/CT. A tabela C2 mostra que ocorreu um predomínio de respostas concordantes.

Pela tabela Resultado - R2 de todas as respostas recolhidas 3300 são de opinião concordante contra 785 de opinião discordante. Isto significa que nas empresas dos respondentes há ações que se alinham a algum tipo de cultura organizacional 
Tabela R2: Total de respostas por diferencial semântico

\begin{tabular}{c|c|c|c|c}
\hline DT & D & I & C & CT \\
\hline 279 & 506 & 832 & 2270 & 1030 \\
\hline 785 & & \multicolumn{2}{|c|}{3300} \\
\hline
\end{tabular}

\section{Grau de concordância}

A tabela Resultado - R3 sintetiza as respostas estratificadas segundo a tipologia organizacional. As colunas "Dt" e "Ct" expressam respectivamente o número de respondentes discordantes e concordantes da tipologia utilizando a proposta de Macnaughton (1996): $50 \%$ do valor de "indiferente" é considerado "concordante" e 50\% do valor "indiferente" se considera "discordante". Dessa forma, a discordância é obtida pela soma dos respondentes com DT (discordo totalmente), D (discordo) e $50 \%$ de I (Indiferente); a concordância é obtida pela soma dos respondentes com CT (concordo totalmente), C (concordo) e 50\% de I (Indiferente).

Ou seja, no que se refere a um item ou proposição:

$$
D_{i}=D T+D+I / 2 \quad C_{i}=C+C T+I / 2
$$

Os níveis de concordância e discordância do tipo de cultura organizacional (Dt e Ct) são construídos de forma semelhante a Dt e Ct:.

$$
D_{t}=\sum D T+\sum D+\frac{\sum I}{2} \quad C_{t}=\sum C+\sum C T+\frac{\sum I}{2}
$$

Tabela R.3: respostas obtidas de acordo com o tipo de cultura organizacional

\begin{tabular}{c|c|c|c|c}
\hline TIPODE CULTURA ORGANZACIONAL & Dt & $\mathbf{C t}$ & $\mathbf{G C t}$ & Interpretação do GCt \\
\hline AUTONOMIA (A) & 169.0 & 486.0 & 74.2 & moderada \\
\hline INOVA ÇÁ O(I) & 291.0 & 693.0 & 70.4 & moderada \\
\cline { 2 - 5 } CA PACDADE DE ASSUMIR RISCOS (CR) & 189.5 & 548.5 & 74.3 & moderada \\
\hline PRÓ-ATIVIDA DE (PA) & 183.5 & 472.5 & 72.0 & moderada \\
\hline COMPETITIVDADE A GRESSIVA (CA) & 156.0 & 336.0 & 68.3 & baixa \\
\hline FORMAÇÁO DE PA RCERIA (FP) & 79.0 & 413.0 & 83.9 & substancial \\
\hline ORIENTA ÇÃO PA RA O MERCADO (OM) & 133.0 & 767.0 & 85.2 & substancial \\
\hline
\end{tabular}

Além dos níveis de concordância e discordância pode-se calcular o grau de concordância ao tipo de cultura (GCt) pelo oscilador estocástico de Wilder Jr. (1981), também conhecido como indicador de força relativa:

$$
G C_{t}=100-\left(\frac{100}{\frac{C_{t}}{D_{t}}+1}\right)
$$


Quadro 1: Interpretação de valores do grau de concordância

\begin{tabular}{|l|l|}
\hline Valor de GCt & Frase adequada \\
\hline 0,90 ou mais & Uma concordância muito forte \\
\hline $0,80 a+0,89$ & Uma concordância substancial \\
\hline $0,70 a+0,79$ & Uma concordância moderada \\
\hline $0,60 a+0,69$ & Uma concordância baixa \\
\hline $0,50 a+0,59$ & Uma concordância desprezivel \\
\hline $0,40 a+0,49$ & Uma discordância desprezível \\
\hline $0,30 a+0,39$ & Uma discordância baixa \\
\hline $0,20 a+0,29$ & Uma discordância moderada \\
\hline $0,10 a+0,19$ & Uma discordância substancial \\
\hline 0,10 ou menos & Uma discordância muito forte \\
\hline
\end{tabular}

Os valores do grau de concordância (seja do item seja do tipo de cultura organizacional) ficam no intervalo [0;100] e é conveniente haver um acordo quanto ao que é um valor fraco ou forte. Davis (1976, p.70) propõe uma interpretação que pode ser adaptada para os propósitos de concordância e que pode ser vista no quadro 1. Considerando os casos observados na tabela 5.3 pode-se afirmar que as empresas pesquisadas tendem para dois tipos predominantes de cultura organizacional: formação de parceria (FP) e orientação para o mercado (OM).

\section{Tipos de culturas organizacionais observados}

A tabela 4 mostra a tipologia cultural observada em cada empresa respondente. As colunas destacadas mostram os tipos de cultura organizacional com maior mediana. O respondente R2, por exemplo, obteve a maior mediana nos itens referentes à cultura organizacional "orientação para o mercado"; o respondente R3 obteve a maior mediana em autonomia. Trinta e um respondentes apresentaram uma única cultura organizacional como predominante (neste caso a quantidade de modais=1); oito empresas possuem dois tipos de cultura organizacional predominantes. São empresas bi-modais em cultura organizacional. Por exemplo, a respondente R1 tem duas culturas organizacionais predominantes: competitividade agressiva e formação de parceria.

Além destes 39 respondentes (31 com um único tipo e 8 bi-modais) os demais apresentam de 3 a 7 tipos de cultura organizacional. Pode-se afirmar, neste caso, que tais respondentes não possuem cultura organizacional definida. 
Tabela 5.4: Tipologia cultural por respondente

\section{Grau de Aderência}

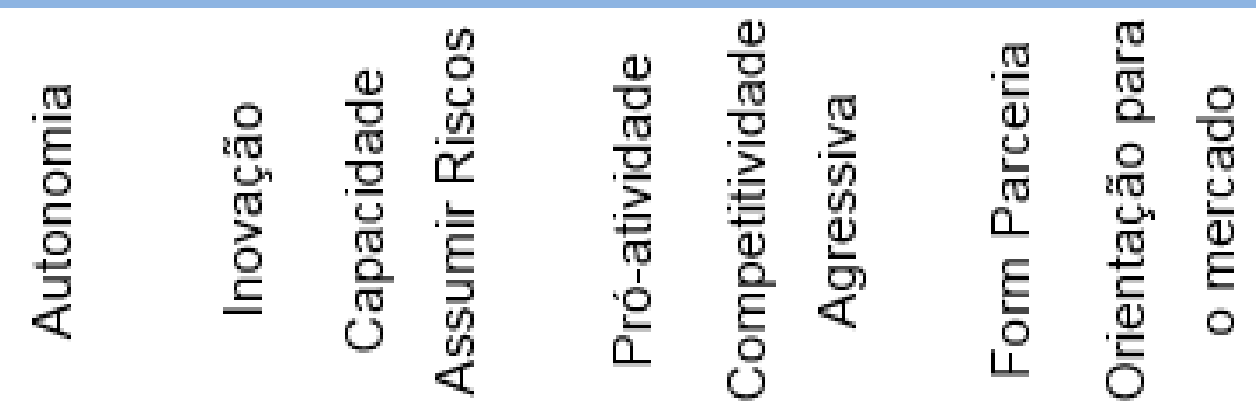

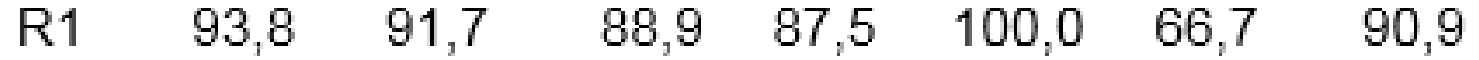

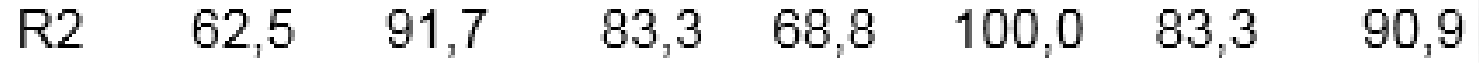

$\begin{array}{llllllll}\text { R3 } & 75,0 & 91,7 & 94,4 & 75,0 & 66,7 & 100,0 & 90,9\end{array}$

R4 $37,5 \quad 41,7 \quad 55,6 \quad 31,3 \quad 58,3 \quad 58,3 \quad 50,0$

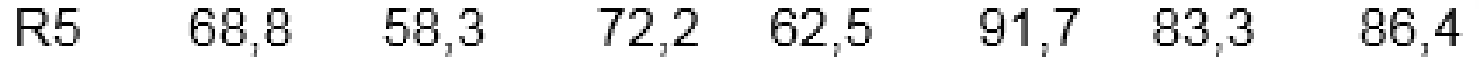

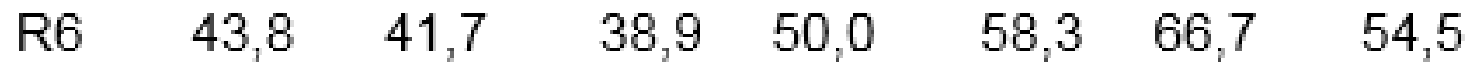

R7 $\quad 37,5 \quad 62,5 \quad 33,3 \quad 43,8 \quad 41,7 \quad 58,3 \quad 54,5$

$\begin{array}{llllllll}\text { R8 } & 87,5 & 87,5 & 88,9 & 100,0 & 75,0 & 75,0 & 100,0\end{array}$

$\begin{array}{llllllll}R 9 & 62,5 & 58,3 & 88,9 & 62,5 & 75,0 & 8,3 & 54,5\end{array}$

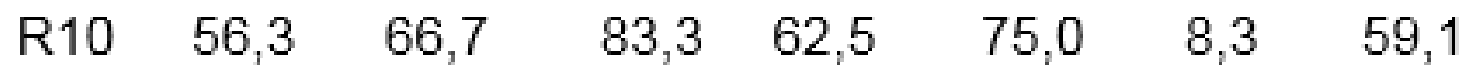

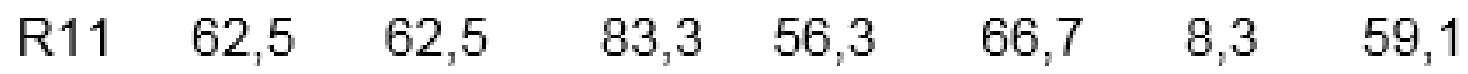

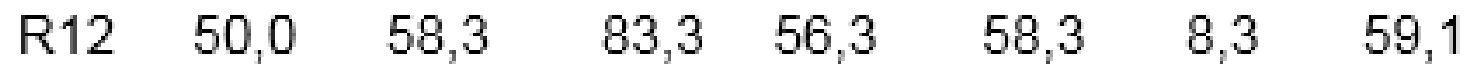

$\begin{array}{llllllll}\mathrm{R} 13 & 37,5 & 41,7 & 83,3 & 50,0 & 66,7 & 8,3 & 59,1\end{array}$

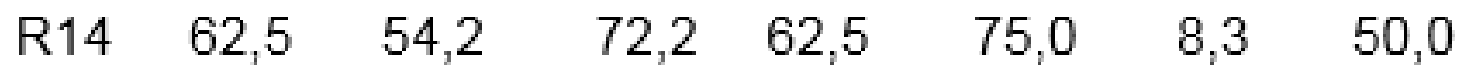

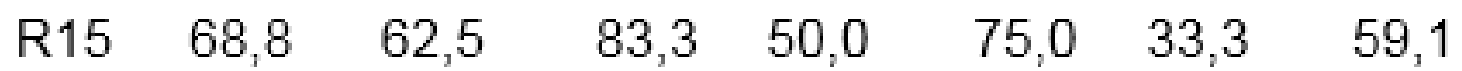

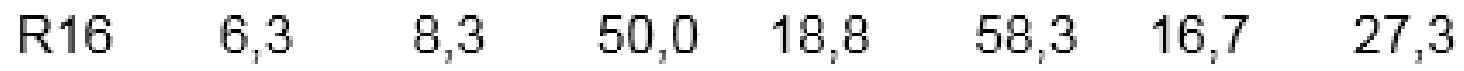

$\begin{array}{lllllll}R & 56,3 & 58,3 & 61,1 & 50,0 & 58,3 & 8,3\end{array} 45,5$

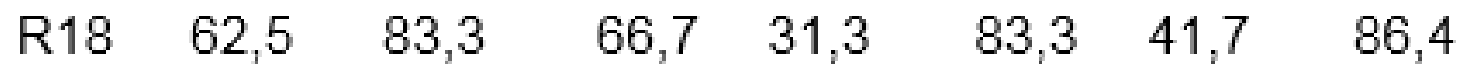




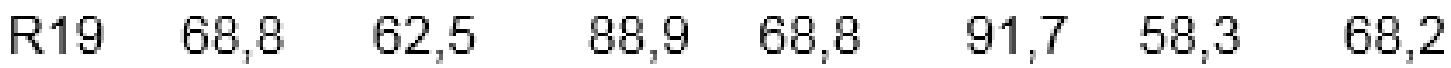

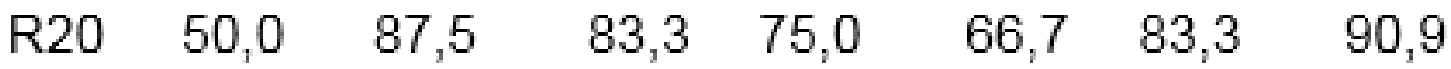

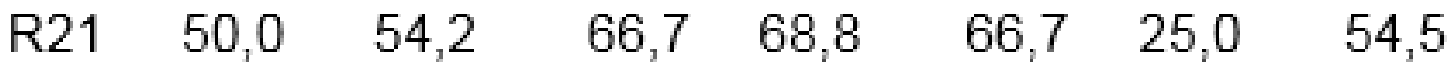

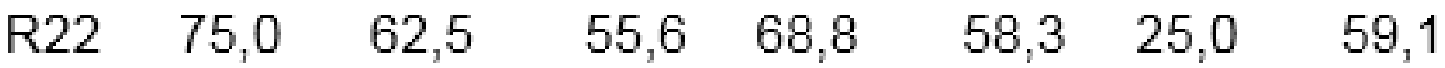

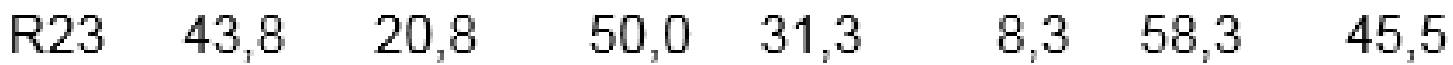

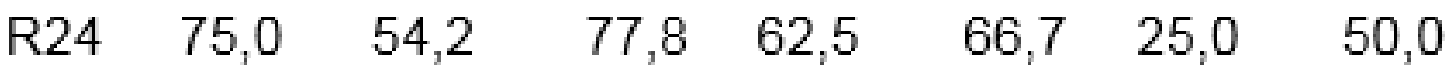

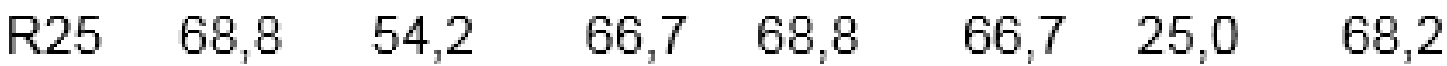

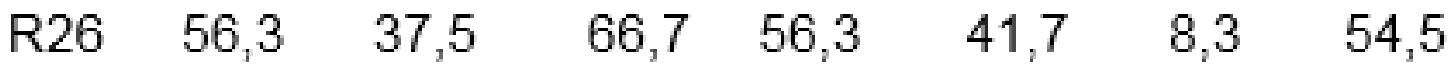
$\begin{array}{llllllll}\text { R27 } & 87,5 & 83,3 & 44,4 & 87,5 & 83,3 & 100,0 & 90,9\end{array}$

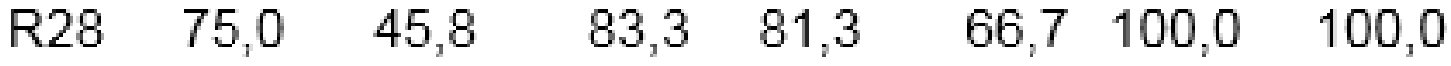

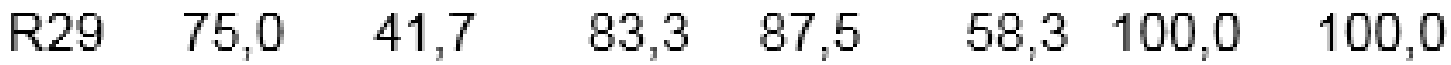

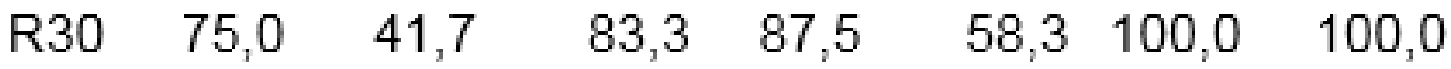
$\begin{array}{llllllll}\text { R31 } & 75,0 & 41,7 & 83,3 & 87,5 & 58,3 & 100,0 & 100,0\end{array}$ $\begin{array}{llllllll}\text { R32 } & 75,0 & 41,7 & 83,3 & 87,5 & 58,3 & 100,0 & 100,0\end{array}$ R33 $\quad 75,0 \quad 54,2 \quad 72,2 \quad 62,5 \quad 66,7 \quad 16,7 \quad 63,6$ $\begin{array}{llllllll}\text { R34 } & 87,5 & 100,0 & 100,0 & 100,0 & 75,0 & 75,0 & 100,0\end{array}$

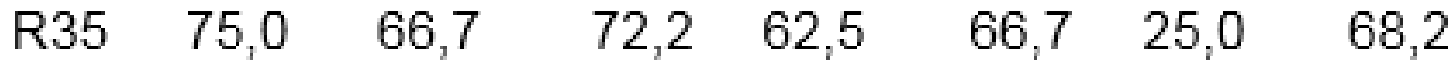
$\begin{array}{llllllll}\text { R36 } & 75,0 & 50,0 & 50,0 & 50,0 & 41,7 & 91,7 & 86,4\end{array}$

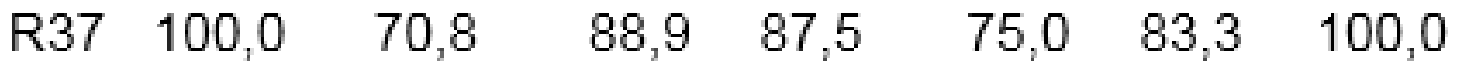

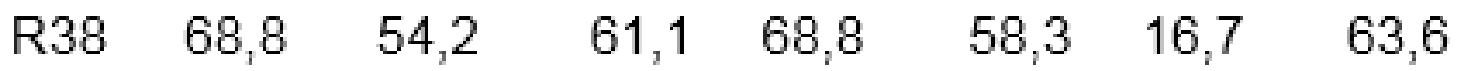
$\begin{array}{llllllll}\text { R39 } & 68,8 & 91,7 & 66,7 & 81,3 & 66,7 & 91,7 & 90,9\end{array}$

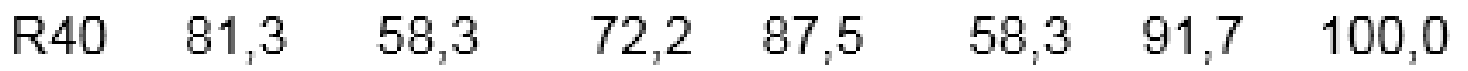
$\begin{array}{llllllll}\text { R41 } & 87,5 & 91,7 & 88,9 & 100,0 & 83,3 & 91,7 & 100,0\end{array}$

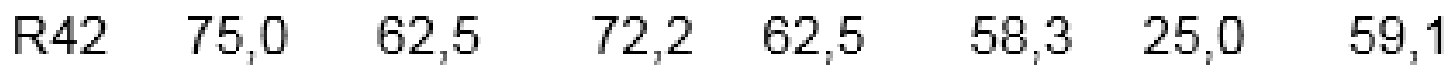

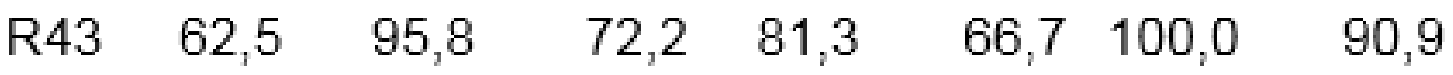




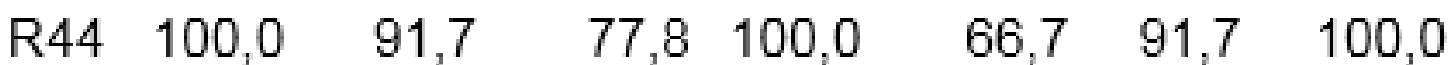

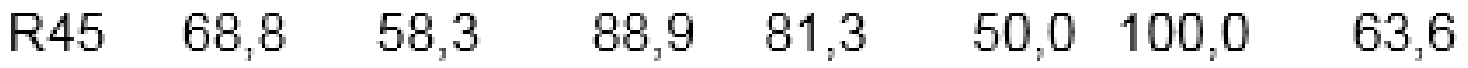
$\begin{array}{llllllll}\text { R46 } & 87,5 & 66,7 & 88,9 & 81,3 & 50,0 & 91,7 & 72,7\end{array}$

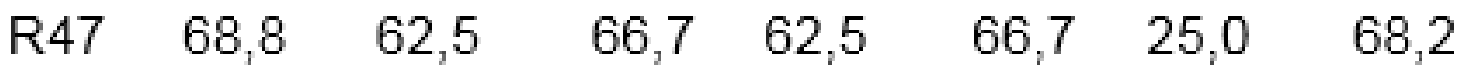

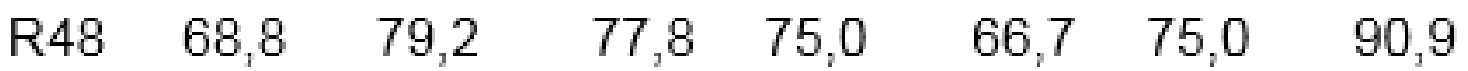

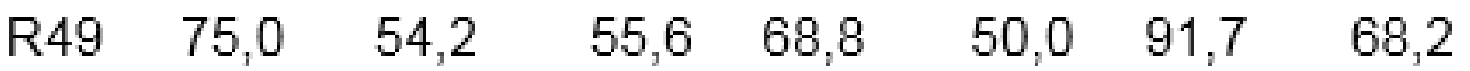

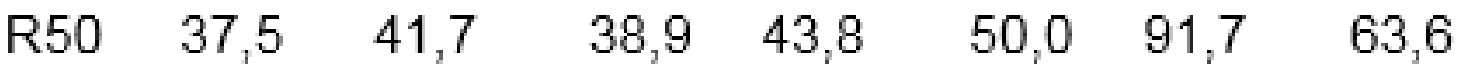

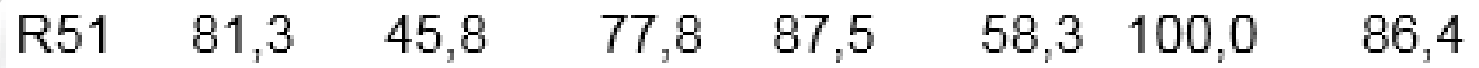

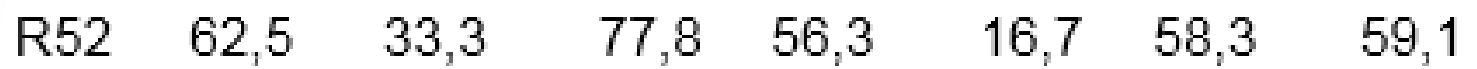

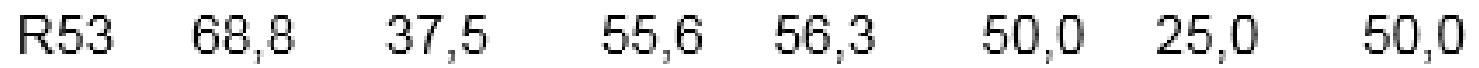

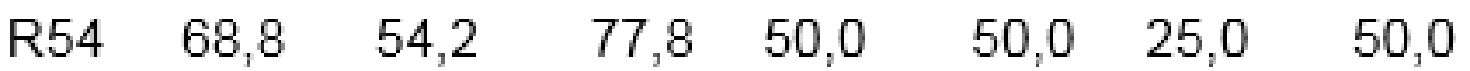
$\begin{array}{llllllll}R 55 & 62,5 & 45,8 & 55,6 & 50,0 & 50,0 & 8,3 & 63,6\end{array}$

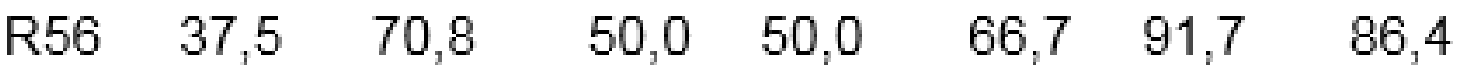
$\begin{array}{llllllll}R 57 & 75,0 & 45,8 & 66,7 & 62,5 & 75,0 & 16,7 & 54,5\end{array}$ $\begin{array}{llllllll}\text { R58 } & 25,0 & 45,8 & 27,8 & 50,0 & 25,0 & 58,3 & 59,1\end{array}$ $\begin{array}{llllllll}\text { R59 } & 75,0 & 91,7 & 72,2 & 56,3 & 100,0 & 83,3 & 95,5\end{array}$

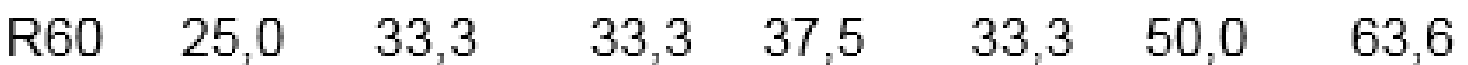

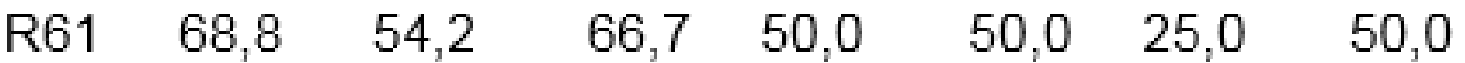
$\begin{array}{llllllll}\text { R62 } & 75,0 & 58,3 & 66,7 & 56,3 & 75,0 & 16,7 & 63,6\end{array}$ $\begin{array}{llllllll}R 63 & 93,8 & 83,3 & 61,1 & 100,0 & 91,7 & 91,7 & 86,4\end{array}$

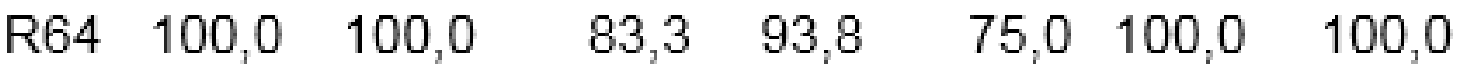
$\begin{array}{llllllll}R 65 & 75,0 & 58,3 & 61,1 & 62,5 & 83,3 & 25,0 & 54,5\end{array}$ $\begin{array}{llllllll}\text { R66 } & 68,8 & 37,5 & 66,7 & 56,3 & 58,3 & 16,7 & 59,1\end{array}$

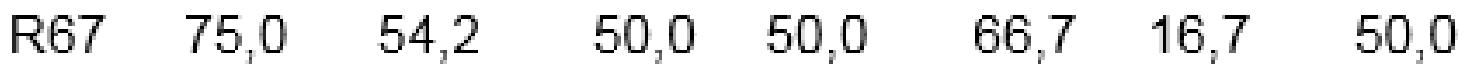
$\begin{array}{llllllll}\text { R6 } & 75,0 & 37,5 & 83,3 & 56,3 & 58,3 & 25,0 & 54,5\end{array}$ 


$\begin{array}{rrrrrrrr}\text { R69 } & 100,0 & 91,7 & 72,2 & 75,0 & 100,0 & 100,0 & 100,0 \\ \text { R70 } & 62,5 & 29,2 & 66,7 & 43,8 & 25,0 & 25,0 & 50,0 \\ \text { R71 } & 75,0 & 62,5 & 66,7 & 68,8 & 58,3 & 25,0 & 54,5 \\ \text { R72 } & 87,5 & 58,3 & 77,8 & 75,0 & 66,7 & 100,0 & 90,9 \\ \text { R73 } & 87,5 & 66,7 & 77,8 & 81,3 & 83,3 & 83,3 & 90,9 \\ \text { R74 } & 75,0 & 62,5 & 72,2 & 56,3 & 83,3 & 25,0 & 68,2 \\ \text { R75 } & 68,8 & 66,7 & 77,8 & 43,8 & 75,0 & 8,3 & 63,6 \\ \text { R76 } & 68,8 & 50,0 & 66,7 & 50,0 & 66,7 & 16,7 & 68,2 \\ \text { R77 } & 62,5 & 29,2 & 44,4 & 6,3 & 16,7 & 100,0 & 63,6 \\ \text { R78 } & 92,9 & 100,0 & 94,4 & 100,0 & 100,0 & 91,7 & 100,0 \\ \text { R79 } & 68,8 & 54,2 & 66,7 & 56,3 & 50,0 & 100,0 & 77,3 \\ \text { R80 } & 43,8 & 41,7 & 72,2 & 56,3 & 33,3 & 25,0 & 59,1 \\ \text { R81 } & 68,8 & 41,7 & 61,1 & 50,0 & 58,3 & 8,3 & 50,0 \\ \text { R82 } & 25,0 & 25,0 & 33,3 & 31,3 & 25,0 & 66,7 & 45,5\end{array}$

A tabela 5.5 mostra a distribuição dos tipos de cultura organizacional, no caso de tipo prevalecente. Pode-se observar que 45,16\% possuem cultura organizacional do tipo 6 (formação de parceria) e 25,81\% do tipo 7: Orientação para o mercado. Estas duas tipologias ocorrem em cerca de $71 \%$ das empresas com tipologia única.

Tabela 5.5: Distribuição dos tipos de cultura organizacional

\begin{tabular}{l|l|r|r}
\hline & \multicolumn{1}{|c|}{ Tipo de cultura Organiza cional } & Qtde & \multicolumn{1}{c}{$\%$} \\
\hline$(1)$ & AUTONOMIA (A) & 4 & 12.90 \\
\hline$(2)$ & INOVAÇÂO (I) & 1 & 3.23 \\
\hline$(3)$ & CAPACIDADE DE ASSUMIR RISCOS (CR) & 1 & 3.23 \\
\hline$(4)$ & PRÓ-ATIVIDADE (PA) & 1 & 3.23 \\
\hline$(5)$ & COMPETITIVIDADE AGRESSIVA (CA) & 2 & 6.45 \\
\hline$(6)$ & FORMAÇÄO DE PARCERIA (FP) & 14 & 45.16 \\
\hline$(7)$ & ORIENTAÇÂO PARA O MERCADO (OM) & 8 & 25.81 \\
\hline & Total $=$ & 31 & \\
\hline
\end{tabular}




\section{Conclusão}

Observou-se que é possível sim propor uma taxionomia para a cultura organizacional de uma empresa com base na orientação empreendedora dos líderes. Para tal foi apresentada uma escala tipo Likert para medir a cultura organizacional, esta escala foi adequadamente validada. Foram também indicadas as proposições relacionadas a cada tipo de cultura organizacional proposto. Não obstante, esta pesquisa determina a taxionomia da Cultura Organizacional Empreendedora, conforme Tabela abaixo

\begin{tabular}{|c|c|c|}
\hline & TIPO DE CULTURA & QTDE \\
\hline 1 & AUTÖNOMA [CA] & 36 \\
\hline 7 & ORIENTAÇÃO PARA O MERCADO & 23 \\
\hline 2 & [COM] & 14 \\
\hline 3 & INOVAÇÄO [CI] & 11 \\
\hline 4 & CAPACIDADE DE ASSUMIR RISCOS \\
\hline 5 & [CCAR] & 4 \\
\hline 6 & FORÓ-ATIVIDADE [CPA] & 2 \\
\hline
\end{tabular}

Os dados coletados foram analisados de forma a testar cada uma das hipóteses. Foram utilizadas estatísticas não paramétricas. Ockert (2005) defende que os dados oriundos das escalas tipo Likert permitem apenas a relação de equivalência (=) e a relação de comparação (>). Esta última é irreflexiva, assimétrica e transitiva. Desta forma os dados coletados com escalas deste tipo aceitam apenas alguns tratamentos matemáticos ou estatísticos (testes não-paramétricos). Portanto a escala de tipo Likert não pretende ser mais que uma escala ordinal; vale dizer, permite a ordenação de indivíduos através da 'favorabilidade' de sua atitude com relação a determinado objeto, mas não apresenta uma base para dizer quanto o indivíduo é mais favorável que outro, nem para medir a quantidade de mudança depois de certa experiência."(SELLTIZ, et al. 1975, p. 415).

Observou-se que culturas definidas, gestores, estudiosos e novos empreendedores poderão desenvolver uma estratégia mais clara e, sobretudo, administrar o seu negócio com mais eficiência. Isso porque, estando atento aos agentes essenciais de uma organização: clientes, fornecedores, funcionários, estruturas políticas e públicas, assim como a comunidade onde a empresa está inserida e outros aspectos macro-econômicos é possível que o gestor de MPEs tenha uma postura pró reativa as estes fenômenos e deixem de adotar comportamentos de reativos ou de cumprimento de demandas, engessando e ameaçando o bom funcionamento de seu negócio. Essa consciência sobre o funcionamento abrange: finanças, clientes, fornecedores, concorrentes (mercado) e organização necessária ao bom funcionamento da MPE para uma tomada de decisão; que não se baseie somente na subjetividade - na intuição - mas em informações armazenadas, comprovadas e tabuladas que compreendem o caminho para decisões estratégicas ao seu negócio. Com a presente pesquisa, pretende-se, então, contribuir com informações científicas para o que se tem pesquisado sobre o tema empreendedorismo e principalmente para a teoria de Cultura Organizacional; visto que, esses elementos traçados e tipologia empreendedora, poderão gerar novos conhecimentos e caminhos para uma expansão de MPEs empreendedoras, diminuindo assim, os riscos e melhorando as possibilidades de sucesso para os novos empreendedores.

\section{REFERÊNCIAS}

ANDER-EGG, E. Introducción a las técnicas de investigación social. Buenos Aires: Nueva Visión, 1978. 
ALVAREZ, Sharaon A.; IRELAND, R. Duane; REUER, Jeffrey J. Entrepreneurship and Strategic Alliances. Journal of Business Venturing, v.21, p.401-404,2006.

ANTONCIC, Bostjan. Risk Taking in Entrepreneurship: Translating the Individual Level Risk. A version into the Organizational Risk Taking. Journal of Enterprising Culture, v.11, n.1, p.123, Mar, 2003.

ATKINSON, Philip. Criando Mudança Cultural. Petrópolis: Vozes, 2000. 376p.

ATUAHENEGIMA, Kwaku; KO, Anthony. An Empirical Investigation of the Effect of Organization Science, v.12, n.1, p.5474, Jan/Feb., 2001.

AUDRETSCH, David; THURIK, Roy. A Model of the Entrepreneurial Economy. Max Planck Institute for Research into Economic Systems Group Entrepreneur ship, Growth and Public Policy, Germany, p.117, May, 2004.

BARNEY, Jay. Firm Resources and Sustained Competitive Advantage. Journal of Management, v.17, n.1, p.99120, 1991.

BARBETTA, P. A. Estatística aplicada às ciências sociais. 5a. ed. Florianópolis: UFSC, 2002.

BAQUERO, G. Testes psicométricos e projetivos: medidas psico-educacionais. São Paulo: Loyola, 1974.

BERNARDES, C. Sociologia Aplicada à Administração - Gerenciando grupos nas organizações. 4a . Edição. São Paulo: Atlas, 1995.

BERTERO, C. O. A Tomada de Decisão nas Organizações. In Handbook de Estudos Organizacionais. Volume 3. São Paulo: Atlas, 2004.

BOYD JR, H.; WESTFALL, R. Pesquisa mercadológica textos e casos. Rio de Janeiro: FGV, 1978.

BROWON, T. E.; DAVIDSSON, P.; WIKLUND, J. An Operationalization of Stevenson's Conceptualization of Entrepreneurship as Opportunity Based Firm Behavior. Strategic Management Journal, v. 22, n.10, p.953-968, Oct, 2001.96.

BURGELMAN, Robert. Corporate Entrepreneurship and Strategic Management: Insigths from a Process Study. Management Science, v.29, p.1349-1364, 1983 a.

CASTANHAR, José Cezar; DIAS, João Ferreira; ESPERANÇA, José Paulo. Orientação Empreendedora, Reconhecimento de Oportunidades e Desempenho em Pequenas e Médias Empresas Brasileiras: Evidências de 2 Estudos de Caso. Salvador, XXX EnANPAD, 2006.

CEI - CENTRO DE EMPREENDEDORISMO E INOVAÇÃO.

Universidade Federal de Goiás. https://cei.ufg.br/n/85351-brasil-esta-no-topo-do-ranking-mundial-de-empreendedorismo\#: :text=Pesquisa\%20Global\%20Entrepreneurship\%20Monitor\%20(GEM,Reino\%20 Unido\%2C\%20Jap\%C3\%A30\%20e\%20Fran\%C3\%A7a\&text=Tr\%C3\%AAs\%20em\%20cada\%20dez\%20 brasileiros,cria\%C3\%A7\%C3\%A30\%20de\%20um\%20neg\%C3\%B3cio\%20pr\%C3\%B3prio. Acessado em 08.12.2020. 
CHILD, J. Organization structure, environment and performance: the role of strategic choice. Sociology, v. 6 , 1972.

CONCEIÇÃO, Márcio Magera. O novo complexo da reestruturação produtiva do Brasil 1. Ed. Rio de Janeiro: Papel Virtual, 2001. V .1.

COVIN, Jeffrey G.; SLEVIN, Dennis P. Strategic Management of Small Firms in Hostile and Begin Environments. Strategic Management Journal, v.10, n.1, p.75-87, Jan/Feb, 1989.

COVIN, Jeffrey G.; COVIN, Teresa Joyce. Competitive Aggressiveness, Environmental Context and Small Firm Performance. Entrepreneurship Theory and Practice, 1990.

COVIN, Jeffrey G.; GREEN, Kimberly M.; SLEVIN, Dennis, P. Strategic Process Effects on the Entrepreneurial Orientation Sales Growth Rate Relationship. Entrepreneurship Theory and Practice, Jan, 2006.

CRESWELL, J.W. Projeto de pesquisa: método qualitativo, quantitativo e misto; tradução Luciana de Oliveira da Rocha - 2 Ed. - Porto Alegre: Artmed, 2007.

CRONBACH, L, MEEHL, P. Construct validity in psychological tests. Psychol Bull 1955; 52: 281-302

DEAL, T. \& KENNEDY, A. Corporate culture: the rites and rituals of corporate life. Massachutes, Addison-Wesley, 1982

DEGEN, R.J.; MELLO, A.A.A. O empreendedor - fundamentos da iniciativa empresarial. São Paulo, McGraw-Hill, 1989.

DONNELLY, Robert. The interrelationship of planning with corporate culture in the creation of shared values. Managerial Planning, v.32, i.6, 1984.

DRUCKER. P. F. Innovation and Entrepreneurship: Practice and Principles. Contributors. Harper \& Row. New York.1985.

ERTHAL, T. C. Manual de Psicometria. 7. ed. Rio de Janeiro: Zahar, 2003. 144 p. ISBN: 85-7110-341-0.

FLEURY, M.T.L. O desvendar da cultura de uma organização: Uma discussão metológica. São Paulo: Atlas 1989.

FLEURY, Afonso; FLEURY, Maria Tereza L. Estratégias empresariais e formação de competências. 2. ed. São Paulo: Atlas, 2001.

FREITAS, M. E. de. Cultura organizacional: formação, tipologia e impacto. São Paulo: Makron McGraw-Hill, 1991. 135p.

FREITAS, A. B. Traços Brasileiros para uma análise Organizacional. In: Citado por MOTTA, F. P.; CALDAS, M. P (Org). Cultura organizacional e cultura brasileira. $1^{\text {a }}$.

ed., 7. Reimpr. São Paulo: Atlas, 2007. 
FRISHAMMAR, Johan; HÖRTE, Sven Åke. The Role of Market Orientation and Entrepreneurial Orientation for New Product Development Performance in Manufacturing Firms. Technology Analysis \& Strategic Management, v.19, n.6, p.765-788, Nov, 2007.

MILLER, D., FRIESEN. P. Innovation in Conservative and Entrepreneurial Firms: Two Models of Strategic Momentum, Strategic Management Journal. v.3, pp. 1-25, 1982.

GEM - GLOBAL ENTREPENEURSHIP MONITOR. Empreendedorismo no Brasil 2007. Instituto Brasileiro da Qualidade e Produtividade, 2008.

HANDY, Charles. Como compreender uma organização. Ed. Jahar, 1976.

HARRISON, Roger. Understanding your organization's character. Harvard Business Review, v.50, n.3, May-June 1972.

HITT, Michael A. et. al. Guest Editors' Introduction to the Special Issue Strategic Entrepreneurship: Entrepreneurial Strategies for Wealth Creation. Strategic Management Journal, v. 22, n. 6/7, p. 479-491, Jun-Jul, 2001.

FERRIER, Walter J. et. al. The Impact of Performance Distress on Aggressive Competitive Behavior: A Reconciliation of Conflicting Views. Managerial and Decision Economics, 23, p. 301-316, 2002.

HOFSTEDE, Geert et. al. Measuring organizational cultures: a qualitative and quantitative study across twenty cases. Administrative Science Quarterly, v.35, p.286-316, 1990.

HORTON, P. B. \& HUNT, C. L. Sociologia. São Paulo: McGraw-Hill do Brasil, 1980.

LUMPKIN, G T.; Dess, Gregory G. Linking Two Dimensions of Entrepreneurial Orientation to Firm Performance. Academy of Management Review, v.21, n. 1, p. 135-172, 1996.

LUMPKIN, G. T.; Dess, G. G. The Role of Entrepreneurial Orientation in Stimulating Effective Corporate Entrepreneurship. Academy of Management Executive, v.19, n. 1, p.147-156, 2005.

McMULLEN, Jeffery S.; SHEPHERD, Dean A. Entrepreneurial Action and the Role of Uncertainty in the Theory or the Entrepreneur. Academy of Management Review, v.31, n.1, p.132-152, 2006.

MILES, Morgan P.; ARNOLD, Danny R. The Relationship Between Marketing Orientation and Entrepreneurial Orientation. Entrepreneurship Theory and Practice, v.15, n.4, p.49-65, 1991.

MILLER, Danny. The Correlates of Entrepreneurship in Three Types of Firms. Management Science, v.39, n.7, p.770791, Jul, 1983.

MOTTA, Fernando C. Prestes; CALDAS, Miguel P. (org.). Cultura Organizacional e Cultura Brasileira. São Paulo: Atlas, 1997.

MOTTA, Paulo Roberto. Transformação Organizacional: a teoria e a prática de inovar. Rio de Janeiro: Qualitymark, 1997. 325p. 
MOTTA, F. P.; CALDAS, M. P. Cultura organizacional e cultura brasileira. $1^{\text {a }}$ ed., 7. São Paulo: Atlas, 2007.

OLIVEIRA JUNIOR, A. B.. O impacto da orientação empreendedora na performance das empresas brasileiras: Evidências de um estudo híbrido. 2010. Dissertação (Mestrado em Administração), Fundação Getúlio Vargas, Rio de Janeiro, 2010.

PALADINI, E.P. Gestão da qualidade: teoria e prática. São Paulo: Atlas, 2000.

PELHAM, A. M.; WILSON, D. T. A Longitudinal study of the impact of Market Structure, Firm Structure, Strategy, and Market Orientation Culture on dimensions of small- firm performance. Journal of the Academy of Marketing Science, v. 24 , n. 1, p. 27-43, 1996.

PETTIGREW, A. M. On studying organizacional cultures. Administrative Science Quarterly, 24(4), 570-581, 1979.

PASQUALI, L. (2003). Psicometria: Teoria dos testes na psicologia e educação. Petropolis, RJ: Vozes

PRATES, M. A. S e BARROS, B. T. O estilo brasileiro de administrar: sumário de um modelo de ação cultural brasileiro com base na gestão empresarial. In: MOITA, F.P. E CALDAS, M. Cultura Organizacional e Cultura Brasileira. São Paulo: Atlas, 2006.

PRAHALAD, C. K., HAMEL, G. Competindo pelo futuro: estratégias inovadoras para obter o controle do seu setor e criar os mercados de amanhã. Rio de Janeiro: Campus, 1995.

REIMANN, Bernard C., WIENER, Y. (1998), Corporate Culture: Avoiding the Elitist Trap, Business Horizons, 31 , 2, 8, 36-44, Mar-Apr 1988.

ROBBINS, S. P. Organizational behavior. 7. ed. Englewood Cliffs, NJ: Prentice Hall, 1996.

ROBBINS, Stephen. Comportamento organizacional. 9 ed.São Paulo: Prentice Hall, 2002.

SANCHES, C.; MEIRELES, M. Lógica para consistente aplicada à Análise Qualitativa de Dados. São Paulo: Atlas, 2010 (no prelo)

SANDBERG, Birgitta. Creating the Marketing for Disruptive Innovation: Market Proactiveness at the Launch Stage. Journal of Targeting, Measurement and Analysis for Marketing, v.11, n.2, p.184-196, 2002.

SARASVATHY, Saras D.; DEW, N. Entrepreneurial Logics for a Technology of Foolishners. Scandinavian Journal of Management, v.21, p.385-406, 2005.

SARASVATHY, Saras D. Causation and Effectuation: Toward a Theorical Shift from Economic Inevitability to Entrepreneurial Contingency. Academy of Management Review,v.26, n. 2, p.243-263,2001.

SASHKIN, M.; KISER, K.J. Gestão da Qualidade Total na Prática. Rio de Janeiro: Campus, 1994.

SCHEIN, Edgar. Psicologia Organizacional. Rio de Janeiro: Prentice-Hall do Brasil, $3^{\text {a }}$ ed., 1982. 208p.

SCHEIN, Edgar H. Coming to a new awareness of organizational culture. Sloan Management Review, v.25, 2, 
1984. In: FREITAS, M. E. Cultura Organizacional: formação, tipologias e impactos. São Paulo: Makron, McGraw-Hill, 1991.

SCHEIN, E. Guia de sobrevivência da cultura corporativa. Rio de Janeiro, José Olympio.

Organization culture and leadership: a dynamic view. San Francisco: Jossey Bass, 1992. 418p.

Culture: the missing concept in organization studies. Administrative Science Quarterly, p.229-240,

1996.

SELLTIZ, C.; JOHODA, M.; DEUTSCH, M.; COOK, S. W. Métodos de pesquisa nas relações sociais. ed. revisada. Trad. Dante Moreira Leite. São Paulo: Universidade de São Paulo, 1975.

SEBRAE - Serviço Brasileiro de Apóio às Micro e Pequena Empresa. Fatores Condicionantes e Taxas de Sobrevivência e Mortalidade das Micro e Pequenas Empresas no Brasil 20032005. Brasília, Ago, 2007.

SETHIA, N; VON GLINOW, M. A. Arriving at four cultures by managing the reward system. In: Kilmann et. al. Gaining control of the corporate culture. San Francisco: Jossey-Bass, 1985.

SHANE, Scott; VENKATRAMAN, S. The Promise of Entrepreneurship as a Field of Research. Academy of Management Review, v.25, n. 1, p.217-226, 2000.

SCHWARTZ, H.; DAVIS S. Matching corporate culture and bussines strategy. Organizational Dynamics, 10. 1981.

SMITH, Peter B.; PETERSON, Mark F. Liderança, Organizações e Cultura. São Paulo: Pioneira, 1994. 219p.

THEVENET, M. A cultura de empresa hoje em dia. Revista de Administração de Empresas. São Paulo, Abr-jun. 1991 p. 32.

TROMPENAARS, Fons Educator. Nas Ondas da Cultura: como entender a diversidade cultural nos negócios. Tradução de Claudiney Fullman. São Paulo: Editora,1994. 199p.

TZOKAS, Nikolaos; CARTER, Sara; KYRIAZOPOULOS, Panagiotis. Marketing and Entrepreneurial Orientation in Small Firms. Enterprise and Innovation Management Studies, v.2, n.1, p.19-33, 2001.

VAN DE VEN, A. H.; POOLE, M. S. Explaining Development and Change in Organizations. Academy of Management Review, v.20, n.3, p.510-540, 1995.

WILKINSON, A.M. The scientist's handbook for writing papers and dissertations. Englewood Cliffs, NJ: Prentice Hall, 1991.

WOOD JR, Thomaz; CALDAS; Miguel P. Transformação e Realidade Organizacional: Uma perspectiva brasileira. São Paulo: Atlas, 1999. 316p.

YLI-RENKO, Helena; JANAKIRAMAN, Ramkumar. How Customer Portfolio Affects New Product Development in Technology Based Entrepreneurial Firms. Journal of Marketing, v.72, p.131-148, Sep, 2008. 


\section{APÊNDICE}

\begin{tabular}{|c|c|c|c|c|c|}
\hline R1 & R2 & R3 & R4 & & \\
\hline & & & & \multicolumn{2}{|r|}{ AUTONOMIA (A) } \\
\hline $\mathrm{x}$ & $\mathrm{X}$ & $\mathrm{x}$ & $\mathrm{x}$ & 1 & A empresa estimula empregados que apresentam sugestões inovadoras para a organização. \\
\hline $\mathrm{x}$ & $\mathrm{X}$ & $\mathrm{x}$ & $\mathrm{x}$ & 2 & A empresa recompensa empregados que apresentam sugestões inovadoras para a organização. \\
\hline $\mathrm{x}$ & não & $\mathrm{x}$ & $\mathrm{x}$ & 3 & Há uma liberdade de ação empreendedora dentro da organização. \\
\hline $\mathrm{x}$ & $\mathrm{X}$ & $\mathrm{x}$ & $\mathrm{x}$ & 4 & Há uma visão dentro da organização para o desenvolvimento de idéia por grupos autônomos \\
\hline $\mathrm{x}$ & $\mathrm{X}$ & $\mathrm{x}$ & $\mathrm{x}$ & 5 & Há liberdade para buscar novas soluções para a melhoria do produto dentro da organização. \\
\hline $\mathrm{x}$ & $\mathrm{X}$ & $\mathrm{x}$ & $\mathrm{x}$ & 6 & Há liberdade para questionamento dos produtos existentes. \\
\hline $\mathrm{x}$ & $\mathrm{x}$ & $\mathrm{x}$ & $\mathrm{x}$ & 7 & Há liberdade para apresentação de novos projetos por algum membro ou grupos autônomos. \\
\hline $\mathrm{x}$ & $\mathrm{x}$ & $\mathrm{x}$ & $\mathrm{x}$ & 8 & O líder aceita novos projetos e os conduz para promovê-los para uma atividade empreendedora. \\
\hline $\mathrm{x}$ & $\mathrm{x}$ & $\mathrm{x}$ & $\mathrm{x}$ & 9 & Há liberdade para adaptações as inovações às normas organizacionais ou do mercado \\
\hline $\mathrm{x}$ & $\mathrm{x}$ & $\mathrm{x}$ & $\mathrm{x}$ & 10 & $\begin{array}{l}\text { Há liberdade, por qualquer membro, para aproveitar os recursos da organização para buscar ou } \\
\text { propor novas idéias. }\end{array}$ \\
\hline $\mathrm{x}$ & $\mathrm{x}$ & $\mathrm{x}$ & $\mathrm{x}$ & 11 & $\begin{array}{l}\text { A empresa proporciona meios para desenvolver e explorar a tecnologia organizacional por qualquer } \\
\text { membro. }\end{array}$ \\
\hline $\mathrm{x}$ & $\mathrm{x}$ & $\mathrm{x}$ & $\mathrm{x}$ & 12 & Há uma gestão participativa entre todos os empregados. \\
\hline $\mathrm{x}$ & $\mathrm{x}$ & $\mathrm{x}$ & $\mathrm{x}$ & 13 & Há apoio para uma tomada de decisão de uma nova ideia. \\
\hline \multirow[t]{2}{*}{$\mathrm{x}$} & $\mathrm{x}$ & $\mathrm{x}$ & $\mathrm{x}$ & 14 & Há um apoio moral e financeiro ao assumir riscos por um ato empreendedor. \\
\hline & & & & \multicolumn{2}{|r|}{ INOVAÇẢO (I) } \\
\hline $\mathrm{x}$ & ox & $\mathrm{x}$ & $\mathrm{x}$ & 15 & A empresa tem uma visão inovadora. \\
\hline $\mathrm{x}$ & $\mathrm{x}$ & $\mathrm{x}$ & $\mathrm{x}$ & 16 & A empresa possui um departamento ou um grupo de Pesquisa e Desenvolvimento. \\
\hline $\mathrm{x}$ & não & $\mathrm{x}$ & $\mathrm{ox}$ & 17 & A empresa está orientada às necessidades não existentes do mercado.| \\
\hline $\mathrm{x}$ & $\mathrm{x}$ & $\mathrm{x}$ & $\mathrm{x}$ & 18 & A empresa tem uma cultura de antecipar tendências futuras para o mercado. \\
\hline $\mathrm{x}$ & $\mathrm{x}$ & $\mathrm{x}$ & $\mathrm{x}$ & 19 & A empresa tem como perfil a busca do pioneirismo no mercado em que atua. \\
\hline $\mathrm{x}$ & $\mathrm{x}$ & $\mathrm{x}$ & $\mathrm{x}$ & 20 & A empresa busca inovações tecnológicas para os produtos existentes do seu portfolio \\
\hline $\mathrm{x}$ & $\mathrm{x}$ & $\mathrm{x}$ & $\mathrm{x}$ & 21 & $\begin{array}{l}\text { A empresa está aberta a melhorias inovadoras de produtos de concorrentes para agregar ao seu } \\
\text { portfolio }\end{array}$ \\
\hline $\mathrm{x}$ & $\mathrm{x}$ & $\mathrm{x}$ & $\mathrm{x}$ & 22 & A empresa busca inovações tecnológicas para a melhoria de seus processos. \\
\hline $\mathrm{x}$ & $\mathrm{x}$ & $\mathrm{x}$ & $\mathrm{x}$ & 23 & Há um ambiente favorável para o desenvolvimento de novos produtos. \\
\hline $\mathrm{x}$ & $\mathrm{x}$ & $\mathrm{x}$ & $\mathrm{x}$ & 24 & $\begin{array}{l}\text { Há um reconhecimento, ou premiação para ideias inovadoras que impactarão nos processos da } \\
\text { organização. }\end{array}$ \\
\hline $\mathrm{x}$ & $\mathrm{x}$ & $\mathrm{x}$ & $\mathrm{x}$ & 25 & $\begin{array}{l}\text { Há um reconhecimento, ou premiação para idéias inovadoras que impactarão melhoria dos } \\
\text { produtos. }\end{array}$ \\
\hline $\mathrm{x}$ & $\mathrm{x}$ & $\mathrm{x}$ & $\mathrm{x}$ & 26 & Há um reconhecimento, ou premiação para idéias inovadoras que promoverão um novo produto. \\
\hline \multirow[t]{2}{*}{$\mathrm{x}$} & $\mathrm{x}$ & $\mathrm{x}$ & $\mathrm{x}$ & 27 & Há um investimento tecnológico para melhoria dos métodos, processos e técnicas da produção. \\
\hline & & & & \multicolumn{2}{|r|}{ CAPACIDADE DE ASSUMIR RISCOS (CA) } \\
\hline $\mathrm{x}$ & $\mathrm{x}$ & $\mathrm{x}$ & $\mathrm{x}$ & 28 & A empresa apóia tendências para novos projetos \\
\hline ox & $\mathrm{x}$ & $\mathrm{x}$ & ox & 29 & Os líderes da empresa assumem riscos sem medo do insucesso. \\
\hline
\end{tabular}




\begin{tabular}{|c|c|c|c|c|c|}
\hline $\mathrm{x}$ & xo & $\mathrm{x}$ & ox & 30 & A empresa abre novas carreiras para atender específicas necessidades dos clientes ou mercado. \\
\hline ox & $\mathrm{x}$ & $\mathrm{x}$ & $\mathrm{x}$ & 31 & Os líderes da empresa adotam uma postura agressiva quanto à natureza do ambiente de negócios. \\
\hline $\mathrm{x}$ & $\mathrm{x}$ & $\mathrm{x}$ & $\mathrm{x}$ & 32 & A empresa aventura-se no desconhecido. \\
\hline $\mathrm{x}$ & $\mathrm{x}$ & $\mathrm{x}$ & $\mathrm{x}$ & 33 & A empresa busca novos produtos dentro do seu segmento. \\
\hline $\mathrm{x}$ & $\mathrm{x}$ & $\mathrm{x}$ & $\mathrm{x}$ & 34 & $\begin{array}{l}\text { A empresa adota uma postura agressiva em situações de tomada de decisões envolvendo } \\
\text { incertezas. }\end{array}$ \\
\hline ox & $\mathrm{x}$ & $\mathrm{x}$ & ox & 35 & A empresa apóia o líder ou um membro da organização que tenha falhado em um novo projeto. \\
\hline ox & ox & $\mathrm{x}$ & ox & E36 & $\begin{array}{l}\text { A empresa está comprometida em elevar o seu nível de endividamento em apostar em um novo } \\
\text { projeto. }\end{array}$ \\
\hline $\mathrm{x}$ & $x$ & $\mathrm{x}$ & $\mathrm{x}$ & 37 & A empresa apóia e materializa projetos inovadores. \\
\hline \multirow[t]{2}{*}{$\mathrm{x}$} & $\mathrm{x}$ & $\mathrm{x}$ & $\mathrm{x}$ & 38 & A empresa aceita assumir riscos para idéias empreendedoras. \\
\hline & & & & \multicolumn{2}{|r|}{ PRÓ-A TIVIDADE (PA) } \\
\hline $\mathrm{x}$ & ox & $\mathrm{x}$ & $\mathrm{x}$ & 39 & A empresa é a primeira a introduzir novos produtos, serviços, tecnologias, técnicas administrativas \\
\hline $\mathrm{x}$ & ox & $\mathrm{x}$ & $\mathrm{x}$ & 40 & A empresa adota uma postura de criar sempre novas ações à frente dos competidores. \\
\hline $\mathrm{x}$ & $\mathrm{x}$ & $\mathrm{x}$ & $\mathrm{x}$ & 41 & A empresa antecipa tendências. \\
\hline $\mathrm{x}$ & $\mathrm{x}$ & $\mathrm{x}$ & $\mathrm{x}$ & 42 & A mudança é parte da cultura da empresa. \\
\hline $\mathrm{x}$ & $\mathrm{x}$ & $\mathrm{x}$ & $\mathrm{x}$ & 43 & Os competidores veem a empresa como inovadora. \\
\hline $\mathrm{x}$ & $\mathrm{x}$ & $x$ & $x$ & 44 & A empresa é rápida em lançar novos produtos. \\
\hline$x$ & $x$ & $x$ & $x$ & 45 & A empresa busca sempre novas parcerias para trazer novas inovações. \\
\hline$x$ & $x$ & $x$ & $x$ & 46 & A empresa tem a vontade e a visão de aproveitar novas oportunidades. \\
\hline$x$ & $x$ & $x$ & $x$ & 47 & A empresa atua antes que seja forçada a reagir às ameaças e oportunidades do ambiente. \\
\hline$x$ & $x$ & $x$ & $x$ & 48 & A empresa é vista como influenciadora ao seu ambiente iniciando novas mudanças. \\
\hline$x$ & $x$ & $x$ & $x$ & 49 & $\begin{array}{l}\text { A empresa é capaz de criar o seu futuro dando vida, por meio de concepção de novos produtos ou } \\
\text { serviços. }\end{array}$ \\
\hline \multirow[t]{2}{*}{$x$} & $x$ & $x$ & $x$ & 50 & $\begin{array}{l}\text { A empresa é capaz de agir de forma oportuna com o propósito de modelar o ambiente, criando } \\
\text { novas demandas. }\end{array}$ \\
\hline & & & & \multicolumn{2}{|r|}{ COMPETITIVIDADE AGRESSIVA (CA) } \\
\hline ox & $x$ & $x$ & ox & 51 & A empresa, ao lidar com concorrentes, inicia ações agressivas. \\
\hline ox & $x$ & $x$ & $x$ & 52 & A empresa cobra atitudes rápidas e estratégicas de seus membros. \\
\hline ox & $x$ & $x$ & $x$ & 53 & A empresa busca resultados imediatos através de novas estratégias para o domínio do mercado. \\
\hline ox & $x$ & $x$ & ox & 54 & A empresa dá muita ênfase à comercialização de produtos e serviços. \\
\hline$x$ & $x$ & $x$ & $x$ & 55 & As ações estratégicas tem uma clareza de alta competitividade e de uma grande velocidade \\
\hline ox & $x$ & $x$ & ox & 56 & A empresa responde rapidamente aos ataques dos competidores. \\
\hline$x$ & $x$ & $x$ & $x$ & 57 & $\begin{array}{l}\text { A empresa realiza pesquisa junto aos usuários finais e clientes para avaliar a qualidade de produtos } \\
\text { ou serviços. }\end{array}$ \\
\hline$x$ & $x$ & $x$ & ox & 58 & Há um controle de qualidade interno em relação aos produtos da concorrência. \\
\hline$x$ & $x$ & $x$ & ox & 59 & Há um alto investimento de marketing para promoção e manutenção dos produtos e ou serviços. \\
\hline$x$ & $x$ & $x$ & ox & 60 & A empresa utiliza muita análise estratégica em seu negócio. \\
\hline ox & $\mathrm{x}$ & ox & ox & E61 & $\begin{array}{l}\text { Os clientes da minha empresa, ao comparar os nossos produtos ao da concorrência, eles os } \\
\text { classificam como sendo muito superior. }\end{array}$ \\
\hline ox & ox & $\mathrm{x}$ & ox & E62 & novas ações estratégicas de marketing. \\
\hline
\end{tabular}




\begin{tabular}{|c|c|c|c|c|c|}
\hline & & & & \multicolumn{2}{|r|}{ FORMAÇÁO DE PARCERIA (FP) } \\
\hline $\mathrm{x}$ & $\mathrm{x}$ & $\mathrm{x}$ & $\mathrm{x}$ & 63 & A empresa foca como estratégia a formação de novas parcerias. \\
\hline $\mathrm{x}$ & $\mathrm{x}$ & $\mathrm{x}$ & $\mathrm{x}$ & 64 & A empresa forma alianças como estratégia de negócios para eliminar as barreiras de entrada. \\
\hline $\mathrm{x}$ & $\mathrm{x}$ & $\mathrm{x}$ & ox & 65 & Ao formar novas parcerias a empresa busca um relacionamento a longo prazo. \\
\hline $\mathrm{x}$ & $\mathrm{x}$ & $\mathrm{x}$ & ox & 66 & A empresa preocupa-se em fortalecer o seu relacionamento com seus clientes. \\
\hline $\mathrm{x}$ & $\mathrm{x}$ & $\mathrm{x}$ & ox & 68 & A empresa preocupa-se em manter um relacionamento amigável com os seus concorrentes. \\
\hline $\mathrm{x}$ & $\mathrm{x}$ & $\mathrm{x}$ & $\mathrm{x}$ & 69 & A empresa busca o fortalecimento de posições-chaves entre os seus agentes internos e externos. \\
\hline $\mathrm{x}$ & $\mathrm{x}$ & $\mathrm{x}$ & $\mathrm{x}$ & 70 & A empresa faz uso da vantagem de parcerias para buscar novas oportunidades. \\
\hline$x$ & $x$ & $x$ & $x$ & 71 & A empresa busca novos aprendizados através de parcerias. \\
\hline$x$ & $x$ & ox & ox & 73 & A empresa possui um histórico de sucesso por meio de parcerias. \\
\hline \multirow[t]{2}{*}{$x$} & $x$ & $x$ & ox & 74 & A empresa busca a proteção e o bem-estar de seus parceiros. \\
\hline & & & & \multicolumn{2}{|r|}{ ORIENTAÇÁO PARA O MERCADO (OM) } \\
\hline$x$ & $x$ & $x$ & $x$ & 75 & A empresa tem uma visão para tornar os seus objetivos em recursos realizáveis. \\
\hline$x$ & $x$ & $x$ & $x$ & 76 & A empresa procura definir tarefas e funções que criem um nova estrutura. \\
\hline$x$ & $x$ & $x$ & $x$ & 77 & $\begin{array}{l}\text { A empresa busca a criação de processos resultantes de uma visão diferenciada do seu meio de } \\
\text { atuação. }\end{array}$ \\
\hline$x$ & $x$ & $x$ & $x$ & 78 & $\begin{array}{l}\text { A empresa atua de forma ativa em acompanhar o seu produto ou serviço em seu mercado de } \\
\text { atuação. }\end{array}$ \\
\hline$x$ & $x$ & $x$ & ox & 79 & A empresa está atenta às tendências do mercado. \\
\hline$x$ & $x$ & $x$ & $x$ & 81 & Os membros da empresa estão atentos às ações dos concorrentes no mercado. \\
\hline$x$ & $\mathrm{x}$ & $x$ & $x$ & 82 & A empresa preocupa-se em atender as necessidades do mercado. \\
\hline$x$ & $x$ & $x$ & ox & 83 & A empresa busca novos produtos que podem surgir segundo as novas tendências. \\
\hline$x$ & $\mathrm{x}$ & $\mathrm{x}$ & ox & 84 & A empresa investe em Marketing e reforça sua marca. \\
\hline$x$ & $x$ & $x$ & $x$ & 85 & $\begin{array}{l}\text { Há um alinhamento de processos e práticas de mercado para a empresa cumprir com as } \\
\text { necessidades do mercado. }\end{array}$ \\
\hline$x$ & $x$ & $x$ & ox & 86 & As informações dos clientes são utilizadas para o desenvolvimento de novos produtos. \\
\hline
\end{tabular}




\section{APÊNDICE}

Quadro 1- Questionário: validação do conteúdo. Respostas dos Especialistas

\begin{tabular}{|c|c|c|c|c|c|c|c|c|c|c|c|c|c|c|c|c|c|c|c|c|c|c|c|c|}
\hline $\mathrm{R} 1$ & R5 & R6 & R7 & R8 & R13 & R15 & R18 & R11 & R12 & $\begin{array}{c}\text { Total } \\
\text { G1 }\end{array}$ & R2 & R9 & R3 & R4 & R10 & R14 & R16 & R17 & R19 & R20 & $\begin{array}{c}\text { Total } \\
\text { G2 }\end{array}$ & PD & & $P$ \\
\hline 5 & 4 & 4 & 5 & 4 & 5 & 5 & 5 & 5 & 4 & 46 & 4 & 5 & 4 & 4 & 4 & 4 & 4 & 3 & 4 & 4 & 40 & 0.60 & $\mathrm{~s}$ & 1 \\
\hline 5 & 4 & 3 & 5 & 3 & 4 & 5 & 2 & 5 & 4 & 40 & 5 & 3 & 3 & 3 & 3 & 2 & 3 & 1 & 5 & 3 & 31 & 0.90 & $\mathrm{~s}$ & 2 \\
\hline 5 & 4 & 4 & 5 & 3 & 5 & 5 & 4 & 1 & 3 & 39 & 3 & 2 & 2 & 2 & 2 & 1 & 5 & 2 & 4 & 2 & 25 & 1.40 & $\mathrm{~s}$ & 3 \\
\hline 4 & 2 & 4 & 5 & 4 & 5 & 5 & 4 & 4 & 5 & 42 & 2 & 5 & 4 & 5 & 5 & 4 & 5 & 4 & 5 & 5 & 44 & $\begin{array}{c}- \\
0.20\end{array}$ & não & 4 \\
\hline 4 & 4 & 4 & 5 & 4 & 5 & 5 & 4 & 5 & 5 & 45 & 5 & 4 & 2 & 5 & 5 & 1 & 5 & 4 & 5 & 5 & 41 & 0.40 & $\mathrm{~s}$ & 5 \\
\hline 4 & 3 & 5 & 5 & 4 & 5 & 5 & 4 & 5 & 4 & 44 & 3 & 3 & 4 & 4 & 4 & 4 & 5 & 4 & 4 & 4 & 39 & 0.50 & $\mathrm{~s}$ & 6 \\
\hline 5 & 4 & 4 & 5 & 4 & 5 & 5 & 4 & 4 & 4 & 44 & 4 & 4 & 4 & 5 & 5 & 4 & 4 & 4 & 4 & 4 & 42 & 0.20 & não & 7 \\
\hline 5 & 3 & 4 & 4 & 4 & 5 & 4 & 4 & 3 & 3 & 39 & 4 & 4 & 4 & 4 & 4 & 4 & 4 & 4 & 4 & 4 & 40 & $\begin{array}{c}- \\
0.10\end{array}$ & não & 8 \\
\hline 5 & 2 & 4 & 5 & 4 & 5 & 5 & 4 & 4 & 5 & 43 & 4 & 5 & 4 & 4 & 4 & 4 & 4 & 3 & 4 & 4 & 40 & 0.30 & não & 9 \\
\hline 4 & 2 & 4 & 4 & 4 & 5 & 4 & 4 & 2 & 5 & 38 & 5 & 4 & 4 & 4 & 4 & 2 & 2 & 4 & 3 & 3 & 35 & 0.30 & não & 10 \\
\hline 4 & 1 & 4 & 4 & 5 & 4 & 4 & 4 & 4 & 3 & 37 & 3 & 3 & 2 & 2 & 2 & 1 & 5 & 4 & 4 & 2 & 28 & 0.90 & $\mathrm{~s}$ & 11 \\
\hline 5 & 4 & 4 & 4 & 4 & 5 & 4 & 4 & 4 & 4 & 42 & 3 & 4 & 4 & 4 & 4 & 4 & 4 & 4 & 4 & 4 & 39 & 0.30 & não & 12 \\
\hline 5 & 1 & 4 & 4 & 4 & 4 & 4 & 4 & 1 & 5 & 36 & 1 & 1 & 3 & 1 & 1 & 1 & 4 & 4 & 4 & 4 & 24 & 1.20 & $\mathrm{~s}$ & 13 \\
\hline 4 & 5 & 4 & 5 & 4 & 5 & 5 & 4 & 5 & 4 & 45 & 5 & 5 & 3 & 4 & 4 & 3 & 2 & 3 & 5 & 5 & 39 & 0.60 & $\mathrm{~s}$ & 14 \\
\hline 2 & 5 & 4 & 4 & 3 & 4 & 4 & 5 & 4 & 2 & 37 & 3 & 3 & 1 & 1 & 1 & 1 & 1 & 1 & 1 & 4 & 17 & 2.00 & $\mathrm{~s}$ & 15 \\
\hline 1 & 5 & 3 & 5 & 5 & 5 & 5 & 4 & 5 & 5 & 43 & 4 & 3 & 4 & 4 & 4 & 2 & 4 & 3 & 5 & 5 & 38 & 0.50 & $\mathrm{~s}$ & 16 \\
\hline 4 & 5 & 4 & 5 & 5 & 4 & 5 & 4 & 5 & 4 & 45 & 4 & 5 & 4 & 4 & 4 & 2 & 4 & 3 & 5 & 4 & 39 & 0.60 & $\mathrm{~s}$ & 17 \\
\hline 5 & 4 & 4 & 4 & 3 & 5 & 4 & 4 & 4 & 5 & 42 & 4 & 3 & 1 & 4 & 4 & 1 & 5 & 4 & 2 & 3 & 31 & 1.10 & $\mathrm{~s}$ & 18 \\
\hline 5 & 5 & 4 & 5 & 3 & 5 & 5 & 5 & 4 & 4 & 45 & 5 & 4 & 1 & 4 & 4 & 2 & 4 & 4 & 5 & 5 & 38 & 0.70 & $\mathrm{~s}$ & 19 \\
\hline 5 & 5 & 4 & 5 & 5 & 5 & 5 & 5 & 4 & 4 & 47 & 5 & 4 & 4 & 4 & 4 & 3 & 5 & 5 & 4 & 4 & 42 & 0.50 & $\mathrm{~s}$ & 20 \\
\hline 5 & 4 & 4 & 5 & 3 & 5 & 5 & 5 & 5 & 4 & 45 & 4 & 4 & 1 & 4 & 4 & 1 & 4 & 4 & 2 & 5 & 33 & 1.20 & $\mathrm{~s}$ & 21 \\
\hline 4 & 5 & 3 & 4 & 4 & 4 & 4 & 4 & 5 & 4 & 41 & 2 & 3 & 2 & 1 & 1 & 1 & 3 & 1 & 1 & 5 & 20 & 2.10 & $\mathrm{~s}$ & 22 \\
\hline 4 & 3 & 3 & 5 & 3 & 4 & 5 & 4 & 5 & 4 & 40 & 4 & 3 & 2 & 1 & 1 & 1 & 4 & 1 & 2 & 5 & 24 & 1.60 & $\mathrm{~s}$ & 23 \\
\hline 3 & 3 & 3 & 5 & 3 & 4 & 5 & 4 & 5 & 4 & 39 & 4 & 3 & 2 & 1 & 1 & 1 & 5 & 1 & 4 & 4 & 26 & 1.30 & $\mathrm{~s}$ & 24 \\
\hline 3 & 5 & 3 & 4 & 4 & 5 & 4 & 5 & 4 & 4 & 41 & 3 & 4 & 2 & 1 & 1 & 1 & 4 & 4 & 2 & 4 & 26 & 1.50 & $\mathrm{~s}$ & 25 \\
\hline 4 & 4 & 4 & 4 & 4 & 5 & 4 & 4 & 5 & 4 & 42 & 3 & 4 & 4 & 4 & 4 & 3 & 4 & 4 & 3 & 4 & 37 & 0.50 & $\mathrm{~s}$ & 26 \\
\hline 1 & 1 & 4 & 4 & 2 & 1 & 4 & 1 & 1 & 3 & 22 & 1 & 1 & 4 & 1 & 1 & 2 & 2 & 4 & 4 & 1 & 21 & 0.10 & não & 27 \\
\hline 4 & 5 & 3 & 4 & 3 & 4 & 4 & 5 & 4 & 5 & 41 & 4 & 4 & 2 & 1 & 1 & 1 & 3 & 4 & 3 & 4 & 27 & 1.40 & $\mathrm{~s}$ & 28 \\
\hline 5 & 3 & 4 & 3 & 4 & 1 & 3 & 2 & 4 & 4 & 33 & 4 & 4 & 4 & 4 & 4 & 3 & 2 & 5 & 5 & 2 & 37 & 0.40 & $\mathrm{~s}$ & 29 \\
\hline 4 & 1 & 1 & 2 & 2 & 2 & 2 & 1 & 5 & 5 & 25 & 5 & 1 & 2 & 1 & 1 & 1 & 2 & 4 & 2 & 3 & 22 & 0.30 & não & 30 \\
\hline 5 & 5 & 4 & 5 & 4 & 5 & 5 & 5 & 5 & 5 & 48 & 3 & 3 & 4 & 4 & 4 & 4 & 4 & 4 & 5 & 5 & 40 & 0.80 & $\mathrm{~s}$ & 31 \\
\hline 5 & 4 & 4 & 5 & 4 & 2 & 5 & 2 & 4 & 5 & 40 & 3 & 2 & 3 & 4 & 4 & 1 & 4 & 4 & 3 & 4 & 32 & 0.80 & $\mathrm{~s}$ & 32 \\
\hline 1 & 1 & 4 & 2 & 3 & 1 & 2 & 1 & 1 & 1 & 17 & 2 & 3 & 2 & 4 & 4 & 1 & 4 & 1 & 1 & 1 & 23 & 0.60 & $\mathrm{~s}$ & 33 \\
\hline 4 & 5 & 3 & 5 & 3 & 5 & 5 & 5 & 5 & 4 & 44 & 4 & 4 & 3 & 4 & 4 & 1 & 4 & 4 & 4 & 4 & 36 & 0.80 & $\mathrm{~s}$ & 34 \\
\hline 5 & 5 & 4 & 4 & 4 & 4 & 4 & 4 & 5 & 5 & 44 & 4 & 2 & 3 & 4 & 4 & 1 & 3 & 4 & 3 & 4 & 32 & 1.20 & $\mathrm{~s}$ & 35 \\
\hline
\end{tabular}




\begin{tabular}{|c|c|c|c|c|c|c|c|c|c|c|c|c|c|c|c|c|c|c|c|c|c|c|c|c|}
\hline 5 & 4 & 4 & 4 & 4 & 4 & 4 & 4 & 5 & 3 & 41 & 3 & 4 & 4 & 3 & 3 & 1 & 3 & 3 & 2 & 5 & 31 & 1.00 & $\mathrm{~s}$ & 37 \\
\hline 1 & 4 & 4 & 4 & 3 & 5 & 4 & 4 & 5 & 4 & 38 & 4 & 4 & 4 & 3 & 3 & 1 & 4 & 2 & 4 & 5 & 34 & 0.40 & $\mathrm{~s}$ & 38 \\
\hline 4 & 4 & 4 & 4 & 4 & 5 & 4 & 4 & 4 & 4 & 41 & 4 & 3 & 2 & 3 & 3 & 1 & 4 & 4 & 4 & 4 & 32 & 0.90 & $\mathrm{~s}$ & 39 \\
\hline 3 & 5 & 4 & 3 & 3 & 5 & 3 & 4 & 4 & 4 & 38 & 5 & 3 & 4 & 3 & 3 & 1 & 3 & 3 & 5 & 5 & 35 & 0.30 & não & 40 \\
\hline 3 & 4 & 2 & 5 & 3 & 5 & 5 & 4 & 5 & 3 & 39 & 4 & 4 & 1 & 2 & 2 & 1 & 2 & 2 & 5 & 5 & 28 & 1.10 & $\mathrm{~s}$ & 41 \\
\hline 4 & 4 & 4 & 5 & 4 & 5 & 5 & 4 & 4 & 4 & 43 & 4 & 4 & 3 & 3 & 3 & 1 & 5 & 4 & 5 & 5 & 37 & 0.60 & $\mathrm{~s}$ & 42 \\
\hline 4 & 4 & 5 & 5 & 5 & 5 & 5 & 5 & 5 & 4 & 47 & 4 & 4 & 4 & 3 & 3 & 1 & 4 & 5 & 4 & 4 & 36 & 1.10 & $\mathrm{~s}$ & 43 \\
\hline 4 & 4 & 4 & 4 & 4 & 5 & 4 & 4 & 5 & 4 & 42 & 2 & 4 & 4 & 3 & 3 & 2 & 3 & 3 & 4 & 4 & 32 & 1.00 & $\mathrm{~s}$ & 44 \\
\hline 4 & 5 & 4 & 3 & 4 & 4 & 3 & 4 & 5 & 4 & 40 & 3 & 4 & 5 & 3 & 3 & 1 & 3 & 3 & 4 & 5 & 34 & 0.60 & $\mathrm{~s}$ & 45 \\
\hline 3 & 5 & 4 & 5 & 3 & 5 & 5 & 4 & 5 & 3 & 42 & 4 & 3 & 1 & 3 & 3 & 1 & 3 & 3 & 4 & 4 & 29 & 1.30 & $\mathrm{~s}$ & 46 \\
\hline 4 & 5 & 4 & 5 & 3 & 5 & 4 & 4 & 5 & 4 & 43 & 4 & 4 & 2 & 3 & 3 & 1 & 4 & 3 & 4 & 4 & 32 & 1.10 & $\mathrm{~s}$ & 47 \\
\hline 5 & 5 & 4 & 4 & 4 & 1 & 3 & 4 & 4 & 4 & 38 & 4 & 4 & 4 & 2 & 2 & 3 & 1 & 2 & 5 & 4 & 31 & 0.70 & $\mathrm{~s}$ & 48 \\
\hline 5 & 4 & 2 & 4 & 4 & 3 & 4 & 4 & 5 & 4 & 39 & 4 & 4 & 4 & 4 & 3 & 4 & 1 & 3 & 5 & 3 & 35 & 0.40 & $\mathrm{~s}$ & 49 \\
\hline 4 & 5 & 3 & 4 & 4 & 5 & 4 & 4 & 4 & 2 & 39 & 4 & 4 & 4 & 4 & 4 & 4 & 1 & 2 & 5 & 3 & 35 & 0.40 & $\mathrm{~s}$ & 50 \\
\hline 5 & 5 & 4 & 3 & 5 & 5 & 3 & 4 & 5 & 5 & 44 & 4 & 4 & 4 & 4 & 4 & 4 & 2 & 3 & 4 & 4 & 37 & 0.70 & $\mathrm{~s}$ & 51 \\
\hline 4 & 4 & 2 & 3 & 5 & 5 & 3 & 4 & 4 & 4 & 38 & 3 & 4 & 3 & 4 & 4 & 3 & 1 & 4 & 5 & 3 & 34 & 0.40 & $\mathrm{~s}$ & 52 \\
\hline 5 & 4 & 4 & 3 & 4 & 5 & 3 & 4 & 2 & 4 & 38 & 2 & 4 & 4 & 4 & 4 & 4 & 2 & 4 & 5 & 4 & 37 & 0.10 & não & 53 \\
\hline 4 & 4 & 5 & 4 & 4 & 5 & 4 & 5 & 5 & 2 & 42 & 3 & 4 & 4 & 4 & 4 & 5 & 3 & 4 & 1 & 5 & 37 & 0.50 & $\mathrm{~s}$ & 54 \\
\hline 5 & 2 & 5 & 3 & 4 & 4 & 3 & 5 & 5 & 3 & 39 & 2 & 4 & 1 & 4 & 4 & 2 & 4 & 4 & 3 & 3 & 31 & 0.80 & $\mathrm{~s}$ & 55 \\
\hline 4 & 5 & 1 & 4 & 3 & 3 & 4 & 4 & 4 & 5 & 37 & 4 & 4 & 1 & 1 & 1 & 1 & 1 & 2 & 2 & 4 & 21 & 1.60 & $\mathrm{~s}$ & 56 \\
\hline 4 & 5 & 4 & 3 & 4 & 4 & 3 & 4 & 2 & 4 & 37 & 3 & 4 & 2 & 4 & 4 & 1 & 3 & 2 & 2 & 2 & 27 & 1.00 & $\mathrm{~s}$ & 57 \\
\hline 4 & 2 & 4 & 5 & 5 & 4 & 5 & 4 & 4 & 4 & 41 & 4 & 2 & 1 & 4 & 4 & 1 & 5 & 3 & 4 & 2 & 30 & 1.10 & $s$ & 58 \\
\hline 4 & 2 & 4 & 5 & 3 & 4 & 5 & 4 & 2 & 4 & 37 & 5 & 2 & 1 & 4 & 4 & 1 & 5 & 4 & 2 & 3 & 31 & 0.60 & $\mathrm{~s}$ & 59 \\
\hline 4 & 2 & 5 & 5 & 5 & 5 & 5 & 5 & 5 & 3 & 44 & 4 & 2 & 1 & 4 & 4 & 1 & 5 & 5 & 5 & 3 & 34 & 1.00 & $\mathrm{~s}$ & 60 \\
\hline 5 & 4 & 5 & 5 & 4 & 4 & 5 & 3 & 4 & 5 & 44 & 3 & 2 & 4 & 5 & 5 & 4 & 3 & 4 & 3 & 2 & 35 & 0.90 & $\mathrm{~s}$ & 63 \\
\hline 4 & 4 & 4 & 5 & 4 & 5 & 5 & 3 & 4 & 4 & 42 & 3 & 4 & 4 & 4 & 4 & 3 & 3 & 5 & 4 & 3 & 37 & 0.50 & $\mathrm{~s}$ & 64 \\
\hline 5 & 4 & 4 & 5 & 4 & 5 & 5 & 5 & 5 & 5 & 47 & 4 & 4 & 2 & 4 & 4 & 2 & 5 & 5 & 5 & 4 & 39 & 0.80 & $\mathrm{~s}$ & 65 \\
\hline 4 & 4 & 4 & 5 & 3 & 5 & 5 & 5 & 4 & 5 & 44 & 4 & 4 & 2 & 3 & 3 & 2 & 5 & 5 & 3 & 4 & 35 & 0.90 & $\mathrm{~s}$ & 66 \\
\hline 5 & 4 & 5 & 5 & 5 & 5 & 5 & 5 & 4 & 5 & 48 & 4 & 4 & 3 & 4 & 4 & 4 & 5 & 5 & 4 & 4 & 41 & 0.70 & $\mathrm{~s}$ & 67 \\
\hline 5 & 3 & 5 & 3 & 5 & 5 & 3 & 5 & 4 & 5 & 43 & 4 & 4 & 1 & 4 & 4 & 2 & 5 & 5 & 4 & 2 & 35 & 0.80 & $\mathrm{~s}$ & 68 \\
\hline 3 & 3 & 4 & 3 & 5 & 5 & 3 & 5 & 4 & 5 & 40 & 3 & 3 & 1 & 5 & 5 & 3 & 4 & 5 & 3 & 3 & 35 & 0.50 & $\mathrm{~s}$ & 69 \\
\hline 4 & 5 & 3 & 3 & 5 & 5 & 3 & 5 & 5 & 4 & 42 & 4 & 4 & 4 & 4 & 4 & 4 & 3 & 5 & 4 & 4 & 40 & 0.20 & não & 70 \\
\hline 4 & 4 & 4 & 3 & 5 & 5 & 3 & 5 & 2 & 3 & 38 & 5 & 4 & 4 & 4 & 4 & 4 & 4 & 3 & 4 & 3 & 39 & 0.10 & não & 71 \\
\hline 4 & 3 & 4 & 3 & 5 & 5 & 3 & 5 & 5 & 4 & 41 & 4 & 4 & 4 & 4 & 4 & 4 & 4 & 4 & 4 & 3 & 39 & 0.20 & não & 72 \\
\hline 5 & 5 & 5 & 5 & 5 & 5 & 5 & 5 & 5 & 5 & 50 & 3 & 4 & 4 & 5 & 5 & 4 & 3 & 5 & 5 & 4 & 42 & 0.80 & $\mathrm{~s}$ & 73 \\
\hline 4 & 5 & 5 & 5 & 5 & 5 & 5 & 5 & 5 & 5 & 49 & 4 & 4 & 4 & 4 & 4 & 4 & 3 & 3 & 5 & 5 & 40 & 0.90 & $\mathrm{~s}$ & 74 \\
\hline 5 & 4 & 4 & 5 & 5 & 5 & 5 & 4 & 5 & 5 & 47 & 5 & 4 & 4 & 5 & 5 & 5 & 5 & 5 & 3 & 5 & 46 & 0.10 & não & 75 \\
\hline 5 & 5 & 5 & 5 & 5 & 4 & 5 & 5 & 3 & 5 & 47 & 4 & 4 & 4 & 4 & 4 & 2 & 3 & 5 & 2 & 5 & 37 & 1.00 & $\mathrm{~s}$ & 76 \\
\hline 5 & 5 & 5 & 5 & 5 & 5 & 5 & 5 & 4 & 4 & 48 & 4 & 4 & 4 & 5 & 5 & 2 & 3 & 5 & 4 & 5 & 41 & 0.70 & $\mathrm{~s}$ & 77 \\
\hline 4 & 4 & 5 & 5 & 5 & 5 & 5 & 5 & 5 & 4 & 47 & 4 & 4 & 4 & 4 & 4 & 2 & 4 & 3 & 4 & 5 & 38 & 0.90 & $\mathrm{~s}$ & 78 \\
\hline 5 & 5 & 1 & 5 & 4 & 3 & 5 & 5 & 4 & 4 & 41 & 5 & 4 & 1 & 1 & 1 & 1 & 3 & 1 & 4 & 4 & 25 & 1.60 & $\mathrm{~s}$ & 79 \\
\hline 4 & 3 & 3 & 5 & 5 & 4 & 5 & 5 & 3 & 3 & 40 & 3 & 4 & 2 & 4 & 4 & 2 & 4 & 4 & 2 & 4 & 33 & 0.70 & $\mathrm{~s}$ & 80 \\
\hline 5 & 4 & 5 & 5 & 3 & 5 & 5 & 5 & 4 & 4 & 45 & 5 & 4 & 1 & 5 & 5 & 3 & 5 & 5 & 1 & 5 & 39 & 0.60 & $\mathrm{~s}$ & 81 \\
\hline
\end{tabular}


Quadro 2 - Consistência interna da tabulação e cálculo do poder discriminatório.

Fonte: Autor

Quadro 6: Estatítica dos Ítens

\begin{tabular}{|c|c|c|c|c|}
\hline & $\begin{array}{l}\text { Scale Mean if } \\
\text { Item Deleted }\end{array}$ & $\begin{array}{l}\text { Scale Variance } \\
\text { if Item Deleted }\end{array}$ & $\begin{array}{c}\text { Corrected Item- } \\
\text { Total } \\
\text { Correlation }\end{array}$ & $\begin{array}{l}\text { Cronbach's } \\
\text { Alpha if Item } \\
\text { Deleted }\end{array}$ \\
\hline p1 & 235,55 & 1427,734 & ,526 & 961 \\
\hline p2 & 236,30 & 1404,537 &, 502 & ,961 \\
\hline p3 & 236,65 & 1387,397 &, 589 & ,961 \\
\hline p5 & 235,55 & 1391,208 & ,724 & ,961 \\
\hline p6 & 235,70 & 1434,958 & ,302 &, 962 \\
\hline p11 & 236,60 & 1399,726 &, 548 & ,961 \\
\hline p13 & 236,85 & 1401,713 &, 400 & ,962 \\
\hline p14 & 235,65 & 1412,029 &, 564 & ,961 \\
\hline p15 & 237,15 & 1373,397 &, 680 & ,961 \\
\hline p16 & 235,80 & 1412,800 &, 425 &, 962 \\
\hline p17 & 235,65 & 1412,450 &, 654 & 961 \\
\hline p18 & 236,20 & 1387,642 & ,701 &, 961 \\
\hline p19 & 235,70 & 1388,747 &, 749 & ,960 \\
\hline p20 & 235,40 & 1420,568 &, 654 & ,961 \\
\hline p21 & 235,95 & 1372,471 &, 827 & 960 \\
\hline p22 & 236,80 & 1371,011 & ,714 & 960 \\
\hline p23 & 236,65 & 1370,345 & ,737 &, 960 \\
\hline p24 & 236,60 & 1376,884 &, 687 & ,961 \\
\hline p25 & 236,50 & 1379,947 & ,711 & ,961 \\
\hline p26 & 235,90 & 1430,200 &, 526 & ,961 \\
\hline p28 & 236,45 & 1381,313 &, 717 & 961 \\
\hline p29 & 236,35 & 1469,818 &,- 240 & 964 \\
\hline p31 & 235,45 & 1423,208 &, 528 & 961 \\
\hline p32 & 236,25 & 1407,566 & ,489 & 961 \\
\hline p33 & 237,85 & 1466,450 &,- 185 &, 964 \\
\hline p34 & 235,85 & 1390,450 & ,818 & 960 \\
\hline p35 & 236,05 & 1395,208 &, 726 & 961 \\
\hline
\end{tabular}




\begin{tabular}{|c|c|c|c|c|}
\hline p37 & 236,25 & 1400,934 & ,656 & ,961| \\
\hline p38 & 236,25 & 1409,250 & ,469 & ,961 \\
\hline p39 & 236,20 & 1391,853 & ,891 & 960 \\
\hline p41 & 236,50 & 1371,632 & ,731 & 960 \\
\hline p42 & 235,85 & 1392,661 & ,787 & 960 \\
\hline p43 & 235,70 & 1391,274 & ,794 & 960 \\
\hline p44 & 236,15 & 1411,082 &, 649 & 961 \\
\hline p45 & 236,15 & 1417,713 &, 435 & ,961 \\
\hline p46 & 236,30 & 1374,432 & ,848 & 960 \\
\hline p47 & 236,10 & 1383,147 & ,878 & 960 \\
\hline p48 & 236,40 & 1436,358 & ,138 & 963 \\
\hline p49 & 236,15 & 1445,187 &, 062 & ,963 \\
\hline p50 & 236,15 & 1444,871 & ,062 & 963 \\
\hline p51 & 235,80 & 1440,274 & , 157 & ,962 \\
\hline p52 & 236,25 & 1435,671 & ,187 & ,962 \\
\hline p54 & 235,90 & 1450,200 &,- 007 & 963 \\
\hline p55 & 236,35 & 1410,555 &, 451 & ,961 \\
\hline p56 & 236,95 & 1376,892 & ,651 & 961 \\
\hline p57 & 236,65 & 1411,082 & ,486 & ,961 \\
\hline p58 & 236,30 & 1387,800 & 645 & ,961 \\
\hline p59 & 236,45 & 1397,839 &, 521 & 961 \\
\hline p60 & 235,95 & 1382,261 & 634 & 961 \\
\hline p63 & 235,90 & 1442,411 & ,097 &, 962 \\
\hline p64 & 235,90 & 1430,937 &, 373 & ,962 \\
\hline p65 & 235,55 & 1393,734 & 815 & 960 \\
\hline p66 & 235,90 & 1394,726 &, 738 & ,961 \\
\hline p67 & 235,40 & 1423,726 &, 584 & ,961 \\
\hline p68 & 235,95 & 1408,682 & ,447 & ,961 \\
\hline p69 & 236,10 & 1426,937 & ,267 & ,962 \\
\hline p73 & 235,25 & 1428,829 & ,417 & ,962 \\
\hline p74 & 235,40 & 1422,147 &, 544 & ,961 \\
\hline p76 & 235,65 & 1408,976 &, 540 & ,961 \\
\hline p77 & 235,40 & 1409,832 &, 649 & ,961 \\
\hline p78 & 235,60 & 1402,884 & ,802 & ,961 \\
\hline
\end{tabular}




\begin{tabular}{|l|l|l|l|r|} 
p79 & 236,55 & 1365,524 &, 673 &, 961 \\
p80 & 236,20 & 1406,274 &, 587 &, 961 \\
p81 & 235,65 & 1406,345 &, 445 &, 962 \\
\hline
\end{tabular}

Quadro 8 - Questionário validado

\begin{tabular}{|c|c|c|c|c|c|c|}
\hline & \multicolumn{6}{|l|}{ Cultura Organizacional } \\
\hline & \multicolumn{6}{|c|}{$\begin{array}{l}\text { Por favor, marque com uma única alternativa que mais identifica com sua percepção alguns } \\
\text { aspectos referentes à cultura organizacional na sua empresa. }\end{array}$} \\
\hline & \multicolumn{6}{|c|}{$\begin{array}{l}\text { Dê a sua opinião marcando um X na coluna mais adequada à sua avaliação sobre a proposição. } \\
\text { Use: DT - DISCORDO TOTALMENTE, D - DISCORDO, I - INDIFERENTE, C - CONCORDO, CT - } \\
\text { CONCORDO TOTALMENTE }\end{array}$} \\
\hline & AUTONOMIA (A) & $\begin{array}{l}\mathrm{D} \\
\mathrm{T}\end{array}$ & D & I & c & СT \\
\hline 1 & $\begin{array}{l}\text { A empresa estimula empregados que apresentam sugestões inovadoras para a } \\
\text { organização. }\end{array}$ & & & & & \\
\hline 2 & $\begin{array}{l}\text { A empresa recompensa empregados que apresentam sugestões inovadoras } \\
\text { para a organização. }\end{array}$ & & & & & \\
\hline 3 & Há uma liberdade de ação empreendedora dentro da organização. & & & & & \\
\hline 5 & $\begin{array}{l}\text { Há liberdade para buscar novas soluções para a melhoria do produto dentro da } \\
\text { organização. }\end{array}$ & & & & & \\
\hline 6 & Há liberdade para questionamento dos produtos existentes. & & & & & \\
\hline 11 & $\begin{array}{l}\text { A empresa proporciona meios para desenvolver e explorar a tecnologia } \\
\text { organizacional por qualquer membro. }\end{array}$ & & & & & \\
\hline 13 & Há apoio para uma tomada de decisão de uma nova idéia. & & & & & \\
\hline 14 & Há um apoio moral e financeiro ao assumir riscos por um ato empreendedor. & & & & & \\
\hline & INOVAÇAO (I) & $\begin{array}{l}\mathrm{D} \\
\mathrm{T}\end{array}$ & $\mathrm{D}$ & I & C & СT \\
\hline 15 & A empresa tem uma visão inovadora. & & & & & \\
\hline 16 & $\begin{array}{l}\text { A empresa possui um departamento ou um grupo de Pesquisa e } \\
\text { Desenvolvimento. }\end{array}$ & & & & & \\
\hline 17 & A empresa está orientada às necessidades não existentes do mercado. & & & & & \\
\hline 18 & A empresa tem uma cultura de antecipar tendências futuras para o mercado. & & & & & \\
\hline 19 & A empresa tem como perfil a busca do pioneirismo no mercado em que atua. & & & & & \\
\hline 20 & $\begin{array}{l}\text { A empresa busca inovaçőes tecnológicas para os produtos existentes do seu } \\
\text { portfolio }\end{array}$ & & & & & \\
\hline 21 & $\begin{array}{l}\text { A empresa está aberta a melhorias inovadoras de produtos de concorrentes } \\
\text { para agregar ao seu portfolio }\end{array}$ & & & & & \\
\hline
\end{tabular}


22 A empresa busca inovaç̃oses tecnológicas para a melhoria de seus processos.

23 Há um ambiente favorável para o desenvolvimento de novos produtos.

24 Há um reconhecimento, ou premiação para idéias inovadoras que impactarão nos processos da organização.

25 Há um reconhecimento, ou premiação para idéias inovadoras que impactarảo melhoria dos produtos.

26 um novo produto.

\begin{tabular}{|c|c|c|c|c|c|c|}
\hline & CAPACIDADE DE ASSUMIR RISCOS (CA) & $\begin{array}{l}\mathrm{D} \\
\mathrm{T}\end{array}$ & D & I & $\mathrm{C}$ & СT \\
\hline 28 & A empresa apóia tendências para novos projetos & & & & & \\
\hline 29 & Os líderes da empresa assumem riscos sem medo do insucesso. & & & & & \\
\hline 31 & $\begin{array}{l}\text { Os líderes da empresa adotam uma postura agressiva quanto à natureza do } \\
\text { ambiente de negócios. }\end{array}$ & & & & & \\
\hline 32 & A empresa aventura-se no desconhecido. & & & & & \\
\hline 33 & A empresa busca novos produtos dentro do seu segmento. & & & & & \\
\hline 34 & $\begin{array}{l}\text { A empresa adota uma postura agressiva em situações de tomada de decisões } \\
\text { envolvendo incertezas. }\end{array}$ & & & & & \\
\hline 35 & $\begin{array}{l}\text { A empresa apóia o líder ou um membro da organização que tenha falhado em } \\
\text { um novo projeto. }\end{array}$ & & & & & \\
\hline 37 & A empresa apóia e materializa projetos inovadores. & & & & & \\
\hline \multirow[t]{2}{*}{38} & A empresa aceita assumir riscos para idéias empreendedoras. & & & & & \\
\hline & PRO-ATIVIDADE (PA) & $\begin{array}{l}\mathrm{D} \\
\mathrm{T}\end{array}$ & $\mathrm{D}$ & I & $\mathrm{C}$ & CT \\
\hline 39 & $\begin{array}{l}\text { A empresa é a primeira a introduzir novos produtos, serviços, tecnologias, } \\
\text { técnicas administrativas. }\end{array}$ & & & & & \\
\hline 41 & A empresa antecipa tendências. & & & & & \\
\hline 42 & A mudança é parte da cultura da empresa. & & & & & \\
\hline 43 & Os competidores vêem a empresa como inovadora. & & & & & \\
\hline 44 & A empresa é rápida em lançar novos produtos. & & & & & \\
\hline 45 & A empresa busca sempre novas parcerias para trazer novas inovaçỏes. & & & & & \\
\hline 46 & A empresa tem a vontade e a visão de aproveitar novas oportunidades. & & & & & \\
\hline \multirow[t]{2}{*}{47} & $\begin{array}{l}\text { A empresa atua antes que seja forçada a reagir às ameaças e oportunidades } \\
\text { do ambiente. }\end{array}$ & & & & & \\
\hline & COMPETITIVIDADE AGRESSIVA (CA) & $\begin{array}{l}\mathrm{D} \\
\mathrm{T}\end{array}$ & D & 1 & $\mathrm{C}$ & CT \\
\hline 55 & $\begin{array}{l}\text { As ações estratégicas tem uma clareza de alta competitividade e de uma } \\
\text { grande velocidade }\end{array}$ & & & & & \\
\hline 56 & A empresa responde rapidamente aos ataques dos competidores. & & & & & \\
\hline
\end{tabular}




\begin{tabular}{|c|c|c|c|c|c|c|}
\hline 57 & $\begin{array}{l}\text { A empresa realiza pesquisa junto aos usuários finais e clientes para avaliar a } \\
\text { qualidade de produtos ou serviços. }\end{array}$ & & & & & \\
\hline 58 & Há um controle de qualidade interno em relação aos produtos da concorrência. & & & & & \\
\hline 59 & $\begin{array}{l}\text { Há um alto investimento de marketing para promoção e manutenção dos } \\
\text { produtos e ou serviços. }\end{array}$ & & & & & \\
\hline 60 & A empresa utiliza muita análise estratégica em seu negócio. & & & & & \\
\hline & FORMAÇAO DE PARCERIA (FP) & $\begin{array}{l}\mathrm{D} \\
\mathrm{T}\end{array}$ & D & I & $\mathrm{C}$ & CT \\
\hline 65 & Ao formar novas parcerias a empresa busca um relacionamento a longo prazo. & & & & & \\
\hline 66 & A empresa preocupa-se em fortalecer o seu relacionamento com seus clientes. & & & & & \\
\hline 67 & $\begin{array}{l}\text { A empresa preocupa-se em fortalecer o seu relacionamento com seus } \\
\text { fornecedores. }\end{array}$ & & & & & \\
\hline 68 & $\begin{array}{l}\text { A empresa preocupa-se em manter um relacionamento amigável com os seus } \\
\text { concorrentes. }\end{array}$ & & & & & \\
\hline 73 & A empresa possui um histórico de sucesso por meio de parcerias. & & & & & \\
\hline 74 & A empresa busca a proteção e o bem-estar de seus parceiros. & & & & & \\
\hline & ORIENTAÇAO PARA O MERCADO (OM) & $\begin{array}{l}\mathrm{D} \\
\mathrm{T}\end{array}$ & D & I & $\mathrm{C}$ & CT \\
\hline 76 & A empresa procura definir tarefas e funçőes que criem um nova estrutura. & & & & & \\
\hline 77 & $\begin{array}{l}\text { A empresa busca a criação de processos resultantes de uma visão diferenciada } \\
\text { do seu meio de atuação. }\end{array}$ & & & & & \\
\hline 78 & $\begin{array}{l}\text { A empresa atua de forma ativa em acompanhar o seu produto ou serviço em } \\
\text { seu mercado de atuação. }\end{array}$ & & & & & \\
\hline 79 & A empresa está atenta às tendências do mercado. & & & & & \\
\hline 80 & Os membros da empresa estão em contato direto com seus clientes. & & & & & \\
\hline 81 & $\begin{array}{l}\text { Os membros da empresa estão atentos às ações dos concorrentes no } \\
\text { mercado. }\end{array}$ & & & & & \\
\hline 82 & A empresa preocupa-se em atender as necessidades do mercado. & & & & & \\
\hline 83 & $\begin{array}{l}\text { A empresa busca novos produtos que podem surgir segundo as novas } \\
\text { tendências. }\end{array}$ & & & & & \\
\hline 84 & A empresa investe em Marketing e reforça sua marca. & & & & & \\
\hline 85 & $\begin{array}{l}\text { Há um alinhamento de processos e práticas de mercado para a empresa } \\
\text { cumprir com as necessidades do mercado. }\end{array}$ & & & & & \\
\hline 86 & $\begin{array}{l}\text { As informações dos clientes são utilizadas para o desenvolvimento de novos } \\
\text { produtos. }\end{array}$ & & & & & \\
\hline
\end{tabular}


Quadro 9: Questionário validado aplicado

\begin{tabular}{|c|c|c|c|c|c|c|c|}
\hline & \multicolumn{7}{|c|}{ Cultura Organizacional } \\
\hline & & $\begin{array}{l}\text { Por favor, marque com uma única alternativa que mais identifica com } \\
\text { aspectos referentes à cultura organizacional na sua e }\end{array}$ & $\begin{array}{l}\text { sua p } \\
\text { mpres }\end{array}$ & & & & \\
\hline PO & $\mathrm{PF}$ & $\begin{array}{l}\text { Dê a sua opinião marcando um X na coluna mais adequada à sua avali } \\
\text { Use: } \\
\text { DT - DISCORDO TOTALMENTE, } \\
\text { INDIFERENTE, C - CONCORDO, CT - CONCORDO TO }\end{array}$ & $\begin{array}{l}\text { ação s } \\
\text { D- DIS } \\
\text { ALME }\end{array}$ & sobre & $a p$ & , I- & \\
\hline & & Proposiçôes & DT & D & $T$ & $\mathrm{C}$ & CT \\
\hline 38 & 1 & A empresa aceita assumir riscos para idéias empreendedoras. & & & & & \\
\hline 34 & 2 & $\begin{array}{l}\text { A empresa adota uma postura agressiva em situaçôes de tomada de } \\
\text { decisões envolvendo incertezas. }\end{array}$ & & & & & \\
\hline 41 & 3 & A empresa antecipa tendências. & & & & & \\
\hline 37 & 4 & A empresa apóia e materializa projetos inovadores. & & & & & \\
\hline 35 & 5 & $\begin{array}{l}\text { A empresa apóia o líder ou um membro da organização que tenha } \\
\text { falhado em um novo projeto. }\end{array}$ & & & & & \\
\hline 28 & 6 & A empresa apóia tendências para novos projetos & & & & & \\
\hline 47 & 7 & $\begin{array}{l}\text { A empresa atua antes que seja forçada a reagir às ameaças e } \\
\text { oportunidades do ambiente. }\end{array}$ & & & & & \\
\hline 78 & 8 & $\begin{array}{l}\text { A empresa atua de forma ativa em acompanhar o seu produto ou } \\
\text { serviço em seu mercado de atuação. }\end{array}$ & & & & & \\
\hline 32 & 9 & A empresa aventura-se no desconhecido. & & & & & \\
\hline 77 & 10 & $\begin{array}{l}\text { A empresa busca a criação de processos resultantes de uma visão } \\
\text { diferenciada do seu meio de atuação. }\end{array}$ & & & & & \\
\hline 74 & 11 & A empresa busca a proteção e o bem-estar de seus parceiros. & & & & & \\
\hline 22 & 12 & $\begin{array}{l}\text { A empresa busca inovaçôes tecnológicas para a melhoria de seus } \\
\text { processos. }\end{array}$ & & & & & \\
\hline 20 & 13 & $\begin{array}{l}\text { A empresa busca inovações tecnológicas para os produtos existentes } \\
\text { do seu portfolio }\end{array}$ & & & & & \\
\hline 33 & 14 & A empresa busca novos produtos dentro do seu segmento. & & & & & \\
\hline 83 & 15 & $\begin{array}{l}\text { A empresa busca novos produtos que podem surgir segundo as novas } \\
\text { tendências. }\end{array}$ & & & & & \\
\hline 45 & 16 & $\begin{array}{l}\text { A empresa busca sempre novas parcerias para trazer novas } \\
\text { inovações. }\end{array}$ & & & & & \\
\hline 39 & 17 & $\begin{array}{l}\text { A empresa é a primeira a introduzir novos produtos, serviços, } \\
\text { tecnologias, técnicas administrativas. }\end{array}$ & & & & & \\
\hline 44 & 18 & A empresa é rápida em lançar novos produtos. & & & & & \\
\hline 21 & 19 & $\begin{array}{l}\text { A empresa está aberta a melhorias inovadoras de produtos de } \\
\text { concorrentes para agregar ao seu portfolio }\end{array}$ & & & & & \\
\hline
\end{tabular}




\begin{tabular}{|c|c|c|c|c|c|c|c|}
\hline \multirow{3}{*}{$\begin{array}{l}79 \\
17 \\
\end{array}$} & 20 & A empresa está atenta às tendências do mercado. & & & & & \\
\hline & 21 & A empresa está orientada às necessidades não existentes do & & & & & \\
\hline & & mercado. & & & & & \\
\hline 1 & 22 & $\begin{array}{l}\text { A empresa estimula empregados que apresentam sugestões } \\
\text { inovadoras para a organização. }\end{array}$ & & & & & \\
\hline 84 & 23 & A empresa investe em Marketing e reforça sua marca. & & & & & \\
\hline 16 & 24 & $\begin{array}{l}\text { A empresa possui um departamento ou um grupo de Pesquisa e } \\
\text { Desenvolvimento. }\end{array}$ & & & & & \\
\hline 73 & 25 & A empresa possui um histórico de sucesso por meio de parcerias. & & & & & \\
\hline 82 & 26 & A empresa preocupa-se em atender as necessidades do mercado. & & & & & \\
\hline 66 & 27 & $\begin{array}{l}\text { A empresa preocupa-se em fortalecer o seu relacionamento com seus } \\
\text { clientes. }\end{array}$ & & & & & \\
\hline 67 & 28 & $\begin{array}{l}\text { A empresa preocupa-se em fortalecer o seu relacionamento com seus } \\
\text { fornecedores. }\end{array}$ & & & & & \\
\hline 68 & 29 & $\begin{array}{l}\text { A empresa preocupa-se em manter um relacionamento amigável com } \\
\text { os seus concorrentes. }\end{array}$ & & & & & \\
\hline & & Proposiçōes & DT & D & $\mathbf{T}$ & $\mathrm{C}$ & CT \\
\hline 76 & 30 & $\begin{array}{l}\text { A empresa procura definir tarefas e funçőes que criem uma nova } \\
\text { estrutura. }\end{array}$ & & & & & \\
\hline 11 & 31 & $\begin{array}{l}\text { A empresa proporciona meios para desenvolver e explorar a } \\
\text { tecnologia organizacional por qualquer membro. }\end{array}$ & & & & & \\
\hline 57 & 32 & $\begin{array}{l}\text { A empresa realiza pesquisa junto aos usuários finais e clientes para } \\
\text { avaliar a qualidade de produtos ou serviços. }\end{array}$ & & & & & \\
\hline 2 & 33 & $\begin{array}{l}\text { A empresa recompensa empregados que apresentam sugestőes } \\
\text { inovadoras para a organização. }\end{array}$ & & & & & \\
\hline 56 & 34 & A empresa responde rapidamente aos ataques dos competidores. & & & & & \\
\hline 46 & 35 & $\begin{array}{l}\text { A empresa tem a vontade e a visåo de aproveitar novas } \\
\text { oportunidades. }\end{array}$ & & & & & \\
\hline 19 & 36 & $\begin{array}{l}\text { A empresa tem como perfil a busca do pioneirismo no mercado em } \\
\text { que atua. }\end{array}$ & & & & & \\
\hline 18 & 37 & $\begin{array}{l}\text { A empresa tem uma cultura de antecipar tendências futuras para o } \\
\text { mercado. }\end{array}$ & & & & & \\
\hline 15 & 38 & A empresa tem uma visão inovadora. & & & & & \\
\hline 60 & 39 & A empresa utiliza muita análise estratégica em seu negócio. & & & & & \\
\hline 42 & 40 & A mudança é parte da cultura da empresa. & & & & & \\
\hline 65 & 41 & $\begin{array}{l}\text { Ao formar novas parcerias a empresa busca um relacionamento a } \\
\text { longo prazo. }\end{array}$ & & & & & \\
\hline
\end{tabular}




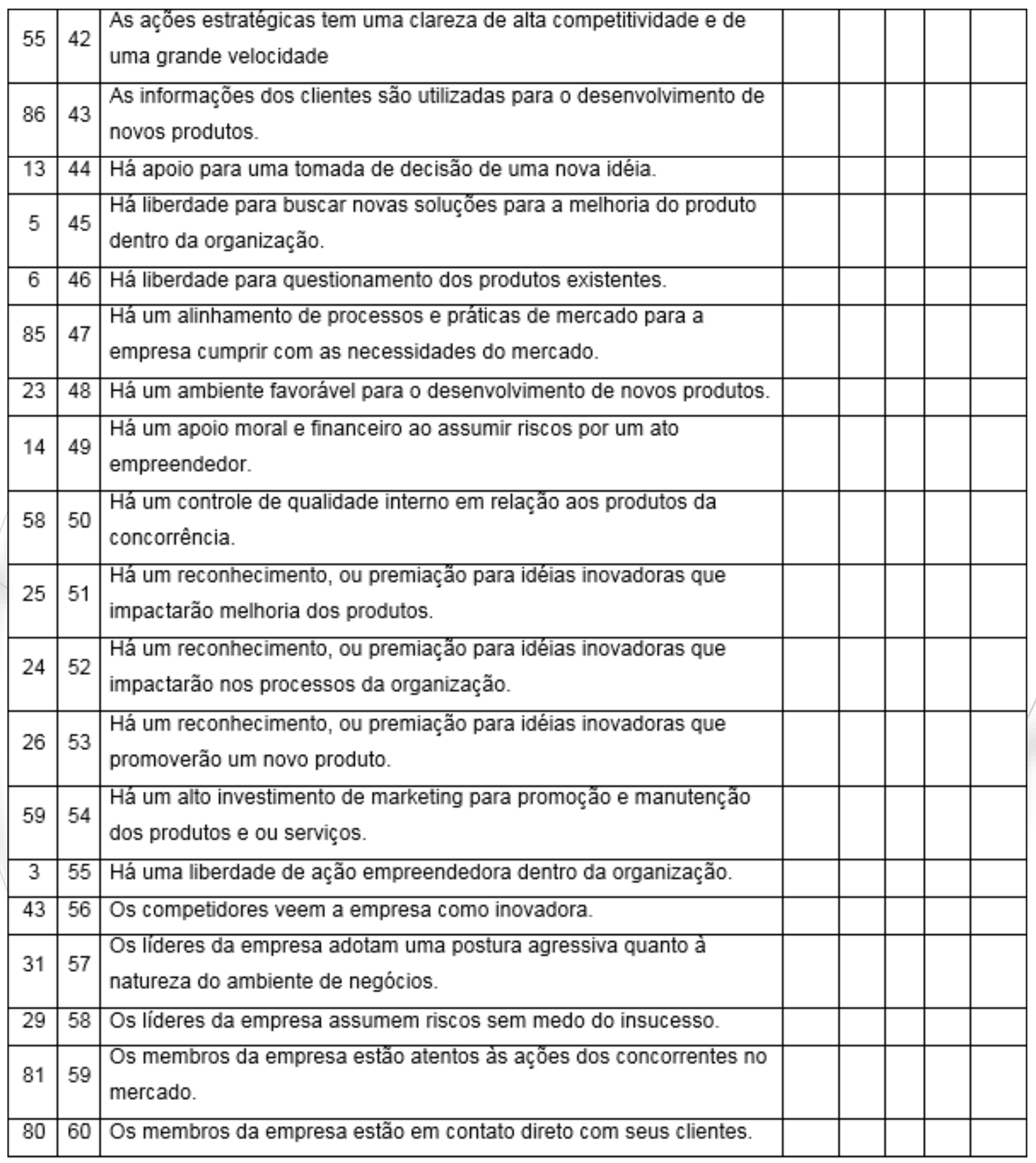


Tabela Resultados R.1: Quantidade de respostas observadas para cada item

\begin{tabular}{|c|c|c|c|c|c|c|}
\hline & AUTONOMIA (A) & DT & D & I & C & CT \\
\hline 1 & $\begin{array}{l}\text { A empresa estimula empregados que apresentam sugestôes } \\
\text { inovadoras para a organização. }\end{array}$ & 3 & 4 & 10 & 43 & 22 \\
\hline 2 & $\begin{array}{l}\text { A empresa recompensa empregados que apresentam sugestões } \\
\text { inovadoras para a organização. }\end{array}$ & 6 & 10 & 18 & 33 & 15 \\
\hline 3 & Há uma liberdade de ação empreendedora dentro da organização. & 2 & 8 & 19 & 37 & 16 \\
\hline 5 & $\begin{array}{l}\text { Há liberdade para buscar novas soluções para a melhoria do } \\
\text { produto dentro da organização. }\end{array}$ & 8 & 6 & 11 & 46 & 10 \\
\hline 6 & Há liberdade para questionamento dos produtos existentes. & 2 & 6 & 9 & 51 & 14 \\
\hline 11 & $\begin{array}{l}\text { A empresa proporciona meios para desenvolver e explorar a } \\
\text { tecnologia organizacional por qualquer membro. }\end{array}$ & 6 & 14 & 28 & 24 & 10 \\
\hline 13 & Há apoio para uma tomada de decisão de uma nova idéia. & 3 & 8 & 9 & 47 & 15 \\
\hline 14 & $\begin{array}{l}\text { Há um apoio moral e financeiro ao assumir riscos por um ato } \\
\text { empreendedor. }\end{array}$ & 12 & 11 & 16 & 28 & 15 \\
\hline & INOVAÇĀO (I) & DT & $\bar{D}$ & $T$ & $\mathrm{C}$ & CT \\
\hline 15 & A empresa tem uma visão inovadora. & 4 & 6 & 17 & 40 & 15 \\
\hline 16 & $\begin{array}{l}\text { A empresa possui um departamento ou um grupo de Pesquisa e } \\
\text { Desenvolvimento. }\end{array}$ & 20 & 22 & 11 & 20 & 9 \\
\hline 17 & $\begin{array}{l}\text { A empresa está orientada às necessidades não existentes do } \\
\text { mercado. }\end{array}$ & 4 & 7 & 25 & 36 & 10 \\
\hline 18 & $\begin{array}{l}\text { A empresa tem uma cultura de antecipar tendências futuras para } 0 \\
\text { mercado. }\end{array}$ & 5 & 8 & 22 & 33 & 14 \\
\hline 19 & $\begin{array}{l}\text { A empresa tem como perfil a busca do pioneirismo no mercado em } \\
\text { que atua. }\end{array}$ & 6 & 5 & 19 & 36 & 16 \\
\hline 20 & $\begin{array}{l}\text { A empresa busca inovações tecnológicas para os produtos } \\
\text { existentes do seu portfolio }\end{array}$ & 4 & 4 & 8 & 38 & 28 \\
\hline 21 & $\begin{array}{l}\text { A empresa está aberta a melhorias inovadoras de produtos de } \\
\text { concorrentes para agregar ao seu portfolio }\end{array}$ & 4 & 6 & 16 & 38 & 18 \\
\hline 22 & $\begin{array}{l}\text { A empresa busca inovaçôes tecnológicas para a melhoria de seus } \\
\text { processos. }\end{array}$ & 4 & 3 & 10 & 40 & 25 \\
\hline 23 & $\begin{array}{l}\text { Há um ambiente favorável para o desenvolvimento de novos } \\
\text { produtos. }\end{array}$ & 5 & 14 & 12 & 41 & 10 \\
\hline 24 & $\begin{array}{l}\text { Há um reconhecimento, ou premiação para idéias inovadoras que } \\
\text { impactarão nos processos da organização. }\end{array}$ & 10 & 12 & 15 & 29 & 16 \\
\hline
\end{tabular}




\begin{tabular}{|c|c|c|c|c|c|c|}
\hline 25 & $\begin{array}{l}\text { Há um reconhecimento, ou premiação para idéias inovadoras que } \\
\text { impactarão melhoria dos produtos. }\end{array}$ & 10 & 14 & 15 & 34 & 9 \\
\hline \multirow[t]{2}{*}{26} & $\begin{array}{l}\text { Há um reconhecimento, ou premiação para idéias inovadoras que } \\
\text { promoverão um novo produto. }\end{array}$ & 8 & 12 & 18 & 32 & 12 \\
\hline & CAPACIDADE DE ASSUMIR RISCOS (CA) & DT & D & I & $\mathrm{C}$ & CT \\
\hline 28 & A empresa apóia tendências para novos projetos & 2 & 6 & 8 & 45 & 21 \\
\hline 29 & Os líderes da empresa assumem riscos sem medo do insucesso. & 2 & 14 & 11 & 36 & 19 \\
\hline 31 & $\begin{array}{l}\text { Os líderes da empresa adotam uma postura agressiva quanto à } \\
\text { natureza do ambiente de negócios. }\end{array}$ & 1 & 13 & 17 & 30 & 21 \\
\hline 32 & A empresa aventura-se no desconhecido. & 18 & 33 & 11 & 16 & 4 \\
\hline 33 & A empresa busca novos produtos dentro do seu segmento. & 1 & 3 & 4 & 40 & 34 \\
\hline 34 & $\begin{array}{l}\text { A empresa adota uma postura agressiva em situações de tomada } \\
\text { de decisões envolvendo incertezas. }\end{array}$ & 6 & 22 & 21 & 25 & 8 \\
\hline 35 & $\begin{array}{l}\text { A empresa apóia o líder ou um membro da organização que tenha } \\
\text { falhado em um novo projeto. }\end{array}$ & 1 & 7 & 15 & 40 & 19 \\
\hline 37 & A empresa apóia e materializa projetos inovadores. & 2 & 2 & 4 & 44 & 30 \\
\hline \multirow[t]{2}{*}{38} & A empresa aceita assumir riscos para idéias empreendedoras. & 1 & 7 & 6 & 45 & 23 \\
\hline & PRÓ-ATIVIDADE (PA) & DT & $\bar{D}$ & $\mathbf{I}$ & $\mathrm{C}$ & CT \\
\hline 39 & $\begin{array}{l}\text { A empresa é a primeira a introduzir novos produtos, serviços, } \\
\text { tecnologias, técnicas administrativas }\end{array}$ & 10 & 15 & 25 & 21 & 11 \\
\hline 41 & A empresa antecipa tendências. & 3 & 12 & 15 & 33 & 19 \\
\hline 42 & A mudança é parte da cultura da empresa. & 4 & 8 & 13 & 45 & 12 \\
\hline 43 & Os competidores veem a empresa como inovadora. & 3 & 7 & 24 & 36 & 12 \\
\hline 44 & A empresa é rápida em lançar novos produtos. & 7 & 10 & 32 & 26 & 7 \\
\hline 45 & $\begin{array}{l}\text { A empresa busca sempre novas parcerias para trazer novas } \\
\text { inovações. }\end{array}$ & 6 & 7 & 14 & 36 & 19 \\
\hline 46 & $\begin{array}{l}\text { A empresa tem a vontade e a visåo de aproveitar novas } \\
\text { oportunidades. }\end{array}$ & 1 & 2 & 12 & 51 & 16 \\
\hline \multirow[t]{2}{*}{47} & $\begin{array}{l}\text { A empresa atua antes que seja forçada a reagir às ameaças e } \\
\text { oportunidades do ambiente. }\end{array}$ & 9 & 6 & 12 & 46 & 9 \\
\hline & COMPETITIVIDADE AGRESSIVA (CA) & DT & $\bar{D}$ & I & $\mathrm{C}$ & CT \\
\hline 55 & $\begin{array}{l}\text { As açőes estratégicas tem uma clareza de alta competitividade e de } \\
\text { uma grande velocidade }\end{array}$ & 4 & 9 & 29 & 32 & 8 \\
\hline 56 & A empresa responde rapidamente aos ataques dos competidores. & 3 & 10 & 20 & 39 & 10 \\
\hline
\end{tabular}




\begin{tabular}{|c|c|c|c|c|c|c|}
\hline 57 & $\begin{array}{l}\text { A empresa realiza pesquisa junto aos usuários finais e clientes para } \\
\text { avaliar a qualidade de produtos ou serviços. }\end{array}$ & 7 & 6 & 10 & 39 & 20 \\
\hline 58 & $\begin{array}{l}\text { Há um controle de qualidade interno em relação aos produtos da } \\
\text { concorrência. }\end{array}$ & 3 & 11 & 20 & 37 & 11 \\
\hline 59 & $\begin{array}{l}\text { Há um uma alto investimento de marketing para promoção e } \\
\text { manutenção dos produtos e ou serviços. }\end{array}$ & 12 & 25 & 9 & 21 & 15 \\
\hline \multirow[t]{2}{*}{60} & A empresa utiliza muita análise estratégica em seu negócio. & 3 & 10 & 18 & 42 & 9 \\
\hline & FORMAÇĀO DE PARCERIA (FP) & DT & D & $\mathbf{I}$ & $\mathrm{C}$ & CT \\
\hline 65 & $\begin{array}{l}\text { Ao formar novas parcerias a empresa busca um relacionamento a } \\
\text { longo prazo. }\end{array}$ & 3 & 8 & 8 & 43 & 20 \\
\hline 66 & $\begin{array}{l}\text { A empresa preocupa-se em fortalecer o seu relacionamento com } \\
\text { seus clientes. }\end{array}$ & 1 & 1 & 5 & 41 & 34 \\
\hline 67 & $\begin{array}{l}\text { A empresa preocupa-se em fortalecer o seu relacionamento com } \\
\text { seus fornecedores. }\end{array}$ & 1 & 2 & 15 & 40 & 24 \\
\hline 68 & $\begin{array}{l}\text { A empresa preocupa-se em manter um relacionamento amigável } \\
\text { com os seus concorrentes. }\end{array}$ & 2 & 2 & 22 & 37 & 19 \\
\hline 73 & A empresa possui um histórico de sucesso por meio de parcerias. & 14 & 9 & 11 & 31 & 17 \\
\hline \multirow[t]{2}{*}{74} & A empresa busca a proteção e o bem-estar de seus parceiros. & 1 & 2 & 5 & 43 & 31 \\
\hline & ORIENTAÇÁO PARA O MERCADO (OM) & DT & D & $\mathbf{I}$ & $\mathrm{C}$ & CT \\
\hline 76 & $\begin{array}{l}\text { A empresa procura definir tarefas e funções que criem um nova } \\
\text { estrutura. }\end{array}$ & 2 & 6 & 18 & 50 & 5 \\
\hline 77 & $\begin{array}{l}\text { A empresa busca a criação de processos resultantes de uma visão } \\
\text { diferenciada do seu meio de atuação. }\end{array}$ & 3 & 9 & 10 & 45 & 14 \\
\hline 78 & $\begin{array}{l}\text { A empresa atua de forma ativa em acompanhar o seu produto ou } \\
\text { serviço em seu mercado de atuação. }\end{array}$ & 1 & 2 & 8 & 42 & 29 \\
\hline 79 & A empresa está atenta às tendências do mercado. & 1 & 2 & 9 & 52 & 18 \\
\hline 80 & Os membros da empresa estão em contato direto com seus clientes. & 1 & 2 & 4 & 36 & 39 \\
\hline 81 & $\begin{array}{l}\text { Os membros da empresa estão atentos às ações dos concorrentes } \\
\text { no mercado. }\end{array}$ & 1 & 6 & 15 & 34 & 26 \\
\hline 82 & A empresa preocupa-se em atender as necessidades do mercado. & 1 & 0 & 5 & 47 & 29 \\
\hline 83 & $\begin{array}{l}\text { A empresa busca novos produtos que podem surgir segundo as } \\
\text { novas tendências. }\end{array}$ & 3 & 3 & 8 & 45 & 23 \\
\hline 84 & A empresa investe em Marketing e reforça sua marca. & 3 & 13 & 12 & 36 & 18 \\
\hline 85 & $\begin{array}{l}\text { Há um alinhamento de processos e práticas de mercado para a } \\
\text { empresa cumprir com as necessidades do mercado. }\end{array}$ & 3 & 9 & 11 & 48 & 11 \\
\hline 86 & $\begin{array}{l}\text { As informações dos clientes são utilizadas para o desenvolvimento } \\
\text { de novos produtos. }\end{array}$ & 3 & 5 & 8 & 49 & 17 \\
\hline
\end{tabular}

